\title{
Dinâmica e estimativas da temperatura e umidade relativa do ar em viveiros protegidos com diferentes sombreamentos
}

\author{
Daniela Roberta BORELLA ${ }^{*}$, Adilson Pacheco de SOUZA ${ }^{1,2}$, Kalisto Natan Carneiro SILVA ${ }^{2}$ \\ Leonardo Martins Moura dos SANTOS ${ }^{2}$, Elen Silma Oliveira Cruz XIMENES 3 , Alison Martins dos ANJOS 2 2Instituto de Ciências Agrárias e Ambientais, Universidade Federal de Mato Grosso, Sinop, MT, Brasil. 2Programa de Pós-Graduação em Agronomia, Universidade Federal de Mato Grosso, Sinop, MT, Brasil. *E-mail: drborella@gmail.com \\ ${ }^{1}$ Programa de Pós-Graduação em Física Ambiental, Universidade Federal de Mato Grosso, Cuiabá, MT, Brasil. \\ (Orcid: 0000-0003-2941-2116; 0000-0003-4076-1093; 0000-0001-9755-9086; 0000-0002-7558-9679; \\ 0000-0003-4054-7441; 0000-0003-3234-613X)
}

Recebido em 17/11/2020; Aceito em 03/02/2021; Publicado em 10/02/2021. \begin{abstract}
RESUMO: Objetivou-se descrever a dinâmica diária da temperatura (Tar) e umidade relativa do ar (UR) em ambientes protegidos com diferentes telas poliefinas de sombreamento, na região de transição CerradoAmazônia do Mato Grosso; ademais, foram avaliados os usos de regressões de estimativa de Tar e UR nos ambientes sombreados com base nas mesmas variáveis medidas em pleno sol. As avaliações micrometeorológicas foram realizadas em viveiros florestais modulares suspensos, alinhados no sentido LesteOeste, entre junho de 2017 e abril de 2019, sob telas pretas com níveis crescentes de sombreamento (35, 50, 65 e $80 \%$ ) e coloridas/espectrais (termorefletora, vermelha, azul e verde, todas com $50 \%$ de sombreamento). Os dados do monitoramento micrometeorológico foram agrupados em função das estações hídricas regionais (seca, seca-chuvosa, chuvosa e chuvosa-seca), com separação da base de dados por decêndios. Foram empregados 70 e 30\% dos dados para geração e validação das regressões, em cada agrupamento de dados, respectivamente. $\mathrm{Na}$ avaliação do desempenho estatístico das regressões foram empregados os indicadores estatísticos: coeficiente de determinação $\left(\mathrm{R}^{2}\right)$, erro absoluto médio (MBE), raiz quadrada do erro quadrático médio (RMSE) e índice de Willmott (d). Houve dinâmica similar de Tar e UR entre a condição de pleno sol e as telas poliefinas pretas e coloridas ao longo do dia e do ano; porém, com aumento expressivo nos valores médios da Tar e UR nesses ambientes protegidos. Os valores de $\mathrm{R}^{2}$ foram satisfatórios, demonstrando que mais de 60\% da variável dependente (Tar nas telas de sombreamento) está relacionada à variável independente (Tar na condição de pleno sol). O d variou de 0,96 a 0,99, indicando que as regressões de estimativas da Tar e UR ajustadas apresentam desempenho satisfatório para todas as estações hídricas regional nos ambientes sombreados.
\end{abstract}

Palavras-chave: ambientes protegidos; micrometeorologia; indicadores estatísticos; transição CerradoAmazônia.

\section{Dynamics and estimates of air temperature and relative humidity in nurseries protected with different shading}

\begin{abstract}
The objective was to describe the daily dynamics of temperature (Tar) and relative humidity $(\mathrm{RH})$ in protected environments with different polyolefin shading screens in transition region of CerradoAmazonia of Mato Grosso; in addition, the uses regressions of estimation of Tar and RH in shaded environments based on the same variables measured in full sun were evaluated. Micrometeorological assessments were performed in suspended modules forest nurseries, aligned to the East-West direction, between June 2017 and April 2019, under black screens with increasing levels of shading (35, 50, 65 and $80 \%$ ) and colored / spectral (thermo-reflector, red, blue and green, all with 50\% shading). The data of the micrometeorological monitoring were grouped according to the regional water stations (dry, dry-rainy, rainy and rainy-dry), with separation of the database for ten years. 70 and $30 \%$ of the data were used to generation and validation the regressions, in each data group, respectively. In the Statistical performance evaluation of the regressions were used the statistical indicators: coefficient of determination $\left(\mathrm{R}^{2}\right)$, the mean error (MBE), root mean square error (RMSE) and Willmott's index of adjustment (d). There was similar dynamic of Tar and UR between the condition of full sun and the black and colored polyolefin screens throughout the day and year; however, with a significant increase in the mean values of Tar and UR in these protected environments. The $\mathrm{R}^{2}$ values were satisfactory, showing that more than $60 \%$ of the dependent variable (Tar in the shading screens) is related to the independent variable (Tar in full sun). The $\mathrm{d}$ ranged from 0.96 to 0.99, indicating that the adjusted regressions of Tar and UR present satisfactory performance for all regional water stations in shaded environments.
\end{abstract}

Palavras-chave: protected environments; micrometeorology; statistical indicators; Cerrado-Amazônia transition. 


\section{INTRODUÇÃO}

Condições climáticas adversas como o aumento expressivo da temperatura do ar e a diminuição da disponibilidade hídrica causam impactos na distribuição e diversidade dos vegetais (BERGAMASCHI; BERGONCI, 2017). Em regiões tropicais, essas alterações podem afetar as taxas de desenvolvimento e produtividade das plantas (HATFIELD; PRUEGER, 2015), bem como a germinação de sementes, morfologia e arquitetura de raízes, caules e folhas, acúmulo de biomassa e duração dos ciclos vegetativo e reprodutivo (GRAY; BRADY, 2016), sendo que nesses casos, os estádios de reprodução vegetal podem ser acelerados ou delongados, afetando a formação e qualidade do produto final.

Dentre as alternativas recentes para mitigação dos efeitos dos elementos micrometeorológicos no cultivo de espécies agrícolas e florestais (em todo o ciclo da cultura), destaca-se o cultivo protegido, que visa garantir produtividade e qualidade para espécies que apresentam dificuldades de produção em épocas específicas do ano e/ou em determinadas regiões (HOLCMAN; SENTELHAS, 2012).

Segundo Souza et al. (2013) e Santos et al. (2013), a região Médio-Norte e Norte do Estado de Mato Grosso possui elevadas amplitudes térmicas durante o inverno (superiores a $20,0{ }^{\circ} \mathrm{C}$ ), com temperaturas médias mensais variando de $22,96{ }^{\circ} \mathrm{C}$ (julho) a $25,31{ }^{\circ} \mathrm{C}$ (abril), e temperaturas mínimas médias mensais superiores a $15,26{ }^{\circ} \mathrm{C}$ (julho). Associado a essa dinâmica da temperatura, os níveis de radiação global médios mensais nessa região variam de $16,56 \pm 2,82 \mathrm{MJ} \mathrm{m}^{-2}$ $\operatorname{dia}^{-1}$ (fevereiro - mês mais chuvoso da região) a 21,17 $\pm 0,83$ MJ m-2 dia $^{-1}$ (outubro), com aumento da transmissividade atmosférica e do brilho solar entre abril e outubro (SOUZA et al., 2016). Essas condições ambientais limitam a produção qualitativa e quantitativa de algumas espécies vegetais em função dos efeitos negativos supracitados, gerados por condições climáticas adversas.

Essas condições meteorológicas da região supracitada indicam a necessidade de utilização de cultivos em ambientes protegidos, haja visto que, segundo Costa et al. (2017), recomenda-se esse tipo de cultivo em regiões com altas temperaturas, excesso de radiação e períodos longos de chuvas, visando reduzir danos causados nos tecidos celulares de plantas em estado juvenil por estas condições climáticas. Dentre inúmeros danos causados pelas altas temperaturas nas plantas podemos citar alguns, como a desnaturação de membranas, estresse oxidativo, comprometimento na atividade fotossintética e alterações estruturais e metabólicas dos cloroplastos (BALFAGÓN et al., 2019).

Dentre os sistemas de cultivo protegido ocorre uma predominância do uso do plástico, que retém menos calor que o vidro. Recentemente vêm sendo desenvolvidos outros materiais como plásticos de diferentes composições e características físicas, telas aluminizadas ou termorefletoras; todavia, a escolha do tipo de tela e o percentual de sombreamento mais adequado são dependentes da espécie/cultivar e das condições climáticas locais (COSTA et al., 2017; AHEMD et al., 2016).

Associadas às coberturas do ambiente, outras técnicas construtivas vêm sendo empregadas como maiores alturas de pé-direito, cortinas laterais retráteis e nebulização. Contudo, a utilização mais intensa de tecnologias mais eficientes no cultivo protegido embate em possíveis aumentos no custo de produção.
O uso de estufas plásticas e/ou telas de sombreamento modifica o microclima interno através da diminuição da transmissividade da radiação global incidente e, consequentemente, melhora a distribuição espacial e temporal (diurna) da temperatura e umidade relativa do ar. Esses ambientes protegidos mantêm níveis adequados para o crescimento uniforme e melhoram a produtividade de culturas agrícolas e florestais em fase inicial de desenvolvimento (SABINO et al., 2020; AHMED et al., 2019). Além disso, funcionam como barreiras contra insetos (TEITEL et al., 2007) e contribuem para a redução da demanda hídrica das plantas (BORELLA et al., 2020; MONTEIRO et al., 2016).

O controle das variáveis meteorológicas no interior de ambientes protegidos é um processo complexo e dinâmico e depende das condições externas (HOLCMAN; SENTELHAS, 2012). Assim, o entendimento da dinâmica micrometeorológica em ambientes sombreados é fundamental para obter informações que auxiliam no controle do ambiente, seleção e manejo das espécies com melhores adaptações à essas condições microclimáticas (SABINO et al., 2020; AHMED et al., 2019; MONTEIRO et al., 2016; HOLCMAN; SENTELHAS, 2012).

O monitoramento da rotina da temperatura e umidade relativa do ar em pesquisas voltadas para ambientes protegidos pode ser realizado a partir de leituras instantâneas de sensores capacitivos associados a sistemas de aquisição de dados (dataloggers), contudo, em função do número de unidades experimentais, o custo de implantação de um sistema de monitoramento pode ser elevado. Em função das inúmeras aplicações para estudos ecofisiológicos e planejamento da produção de espécies/cultivares adaptadas à sazonalidade climática regional, quando não é possível a construção de séries temporais para Tar e UR em ambientes protegidos, torna-se necessário a aplicação de modelos estatísticos simplificados baseados principalmente na condição ambiental normal (pleno sol).

Nesse sentido, objetivou-se descrever a dinâmica microclimática e ajustar modelos estatísticos de estimativas da temperatura (Tar) e umidade relativa do ar (UR), sob telas poliefinas pretas (em níveis crescentes de sombreamento) e telas coloridas (espectrais) em viveiros suspensos, na região de transição Cerrado-Amazônia brasileira.

\section{MATERIAL E MÉTODOS}

2.1. Região de estudo e instalações (viveiros suspensos)

$O$ estudo foi realizado na região de transição CerradoAmazônia, em Sinop-MT (11 $51^{\circ} 50^{\prime \prime}$ S e $55^{\circ} 29^{\prime} 08^{\prime \prime} \mathrm{W}$ e 384 metros de altitude). Segundo a classificação climática de Köppen, o clima dessa região é caracterizado como Aw (tropical quente e úmido) (SOUZA et al., 2013), com temperaturas médias mensais variando de 24,9 a $27,7{ }^{\circ} \mathrm{C}$ e umidade relativa do ar média mensal oscilando entre 52,0 a $86,0 \%$, respectivamente (Figura 1A e 1B). Nessa região, a radiação global e a insolação média mensal oscilam de 16,8 a 21,2 $\mathrm{MJ} \mathrm{m}$ dia $^{-1}$ e 4,5 a 9,1 horas dia ${ }^{-1}$ (Figura 1C).

A sazonalidade climática da região é definida por duas estações hídricas: chuvosa - de outubro a abril; e seca - maio a setembro (Figura 1D) (SOUZA et al., 2013). A precipitação média anual é de 1.945,0 mm, concentrando mais de 1.700,0 $\mathrm{mm}$ nas estações primavera-verão, enquanto que a evapotranspiração de referência oscila de 105,0 a 170,0 mm 
mês $\mathrm{s}^{-1}\left(3,5\right.$ a $\left.5,5 \mathrm{~mm} \mathrm{dia}^{-1}\right)$, entre os períodos chuvoso e seco da região, respectivamente (Figura 1D).

Nesse estudo, o monitoramento micrometeorológico ocorreu em viveiros suspensos, dispostos no sentido LesteOeste, com dimensões de 3,0 x 1,0 x 1,0 m (comprimento, largura e altura) e a $1,0 \mathrm{~m}$ acima do solo (Figura 2). Como referência, adotou-se a condição de pleno sol, enquanto que as demais unidades experimentais apresentavam coberturas superiores, frontais e laterais de telas poliefinas pretas com indicações comerciais $(35,50,65$ e $80 \%$ de sombreamento),

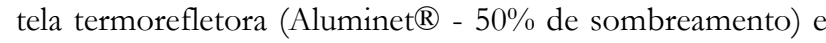
telas poliefinas coloridas vermelha e azul (Chromatinet ${ }^{\circledR}$ $50 \%$ de sombreamento) e verde (Frontinet ${ }^{\circledR}$ - 50\% de sombreamento) (Figura 2).

$\mathrm{Na}$ condição de pleno sol, as medidas de Tar e a UR foram realizadas com uma estação meteorológica automática Instrutemp ITWH-1080, a $20 \mathrm{~m}$ da área experimental, com armazenamento no intervalo de 30 minutos. Em conjunto, foram realizadas medidas convencionais diárias da insolação
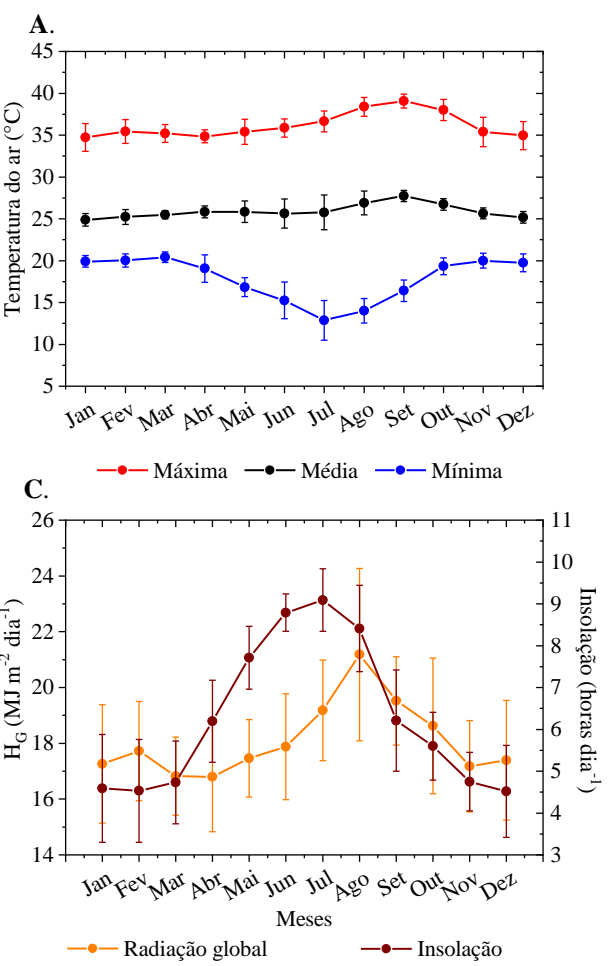

(heliógrafo Campbell-Stokes) para obtenção da radiação global diária com base na razão de insolação e com coeficientes da equação de Angstrom-Prescott calibrados regionalmente na escala mensal (MARTIM et al., 2020).

Nos ambientes protegidos (viveiros) com as telas de sombreamento foram instalados termo-higrômetros com datalogger Instrutemp HT 4000 ICEL a 1,50 m de altura, centralizados no interior de cada unidade experimental, com armazenamento de dados em intervalos de 30 minutos.

Nos ambientes com telas poliefinas pretas, o período de monitoramento micrometeorológico ocorreu entre junho de 2017 a abril de 2019, com o seguinte agrupamento sazonal (estações hídricas do ano): seca (jun-jul-ago), seca/chuvosa (set-out-nov), chuvosa (dez-jan-fev) e chuvosa/seca (marabr). Já para as telas poliefinas coloridas e termorefletora, o monitoramento foi realizado apenas na estação seca de 2017 (junho a setembro), devido à indisponibilidade de equipamentos/sensores para o monitoramento desses microambientes por mais tempo.
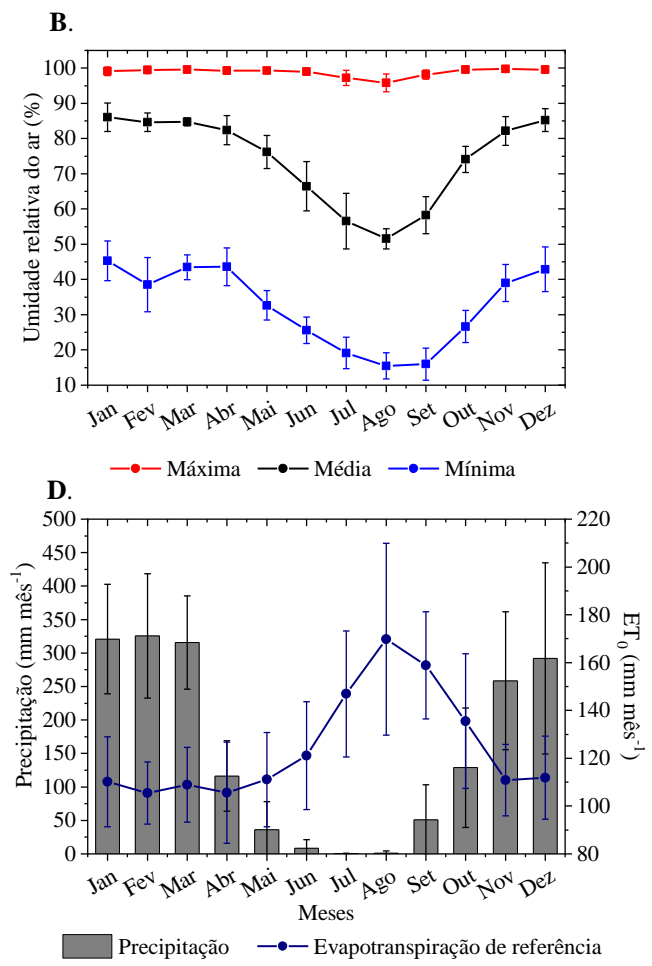

Figura 1. Médias mensais e desvio-padrão da temperatura do ar (A), umidade relativa do ar (B), radiação global e insolação (C), precipitação e evapotranspiração de referência (D), entre 01/09/2010 e 31/12/2019, em Sinop-MT.

Figure 1. Monthly means and standard deviation of air temperature (A), relative air humidity (B), global radiation and sunshine (C), precipitation and reference evapotranspiration (D), between 09/01/2010 and 12/31/2019, in Sinop-MT.

\subsection{Modelos estatísticos de estimativa de Tar e UR}

Os valores diários (médios, máximos e mínimos) da Tar e UR nas condições de sombreamento foram agrupados nas estações hídricas do ano conforme supracitado e, separados por decêndios para gerarem duas bases de dados: uma com $70 \%$ do total dos dados para calibração dos coeficientes estatísticos dos modelos, e outra, com 30\% para validação do desempenho estatístico dos modelos de estimativas. Foram gerados agrupamentos de dados para obtenção de estimativas de valores máximos, médios e mínimos diários de Tar e UR.

Avaliou-se a consistência dos dados e excluíram-se os valores discrepantes decorrentes de erros de leitura ou falhas no sistema de aquisição dos dados, com base nos desvios superiores a $50 \%$ para cada agrupamento supracitado. Foram ajustadas regressões lineares simples entre Tar e UR para cada condição de sombreamento (variável dependente) com Tar e UR na condição de pleno sol (variável independente).

$\mathrm{Na}$ avaliação do desempenho dos modelos gerados foram empregados os indicadores estatísticos MBE - erro quadrado médio (Eq. 1); o RMSE - Raiz Quadrática do Erro Quadrático Médio (Eq. 2); e o dw (Índice de ajustamento de Willmott), conforme (SOUZA et al., 2017). (Eq. 3).

$$
\begin{aligned}
& \mathrm{MBE}=\frac{\sum_{\mathrm{i}=1}^{\mathrm{n}}\left|\mathrm{P}_{\mathrm{i}}-\mathrm{O}_{\mathrm{i}}\right|}{\mathrm{n}} \\
& R \mathrm{MSE}=\left[\frac{\sum_{\mathrm{i}=1}^{\mathrm{n}}\left(\mathrm{P}_{\mathrm{i}}-\mathrm{O}_{\mathrm{i}}\right)^{2}}{\mathrm{n}}\right]^{0,5}
\end{aligned}
$$




$$
d \mathrm{w}=1-\frac{\sum_{\mathrm{i}=1}^{\mathrm{n}}\left(\mathrm{P}_{\mathrm{i}}-\mathrm{O}_{\mathrm{i}}\right)^{2}}{\sum_{\mathrm{i}=1}^{\mathrm{n}}\left(\left|\mathrm{P} \prime_{\mathrm{i}}-\overline{\mathrm{O}}\right|+\left|\mathrm{O} \prime_{\mathrm{i}}-\overline{\mathrm{O}}\right|\right)^{2}}
$$

em que $P_{i}$ - valores estimados; $O_{i}$ - valores medidos; $n$ - número de observações; $\left|P^{\prime}{ }_{i}\right|$ - valor absoluto da diferença $P^{\prime}{ }_{i}-\bar{O} ;\left|O^{\prime}{ }_{i}\right|$ valor absoluto da diferença $O^{\prime}{ }_{i}-\bar{O}$.

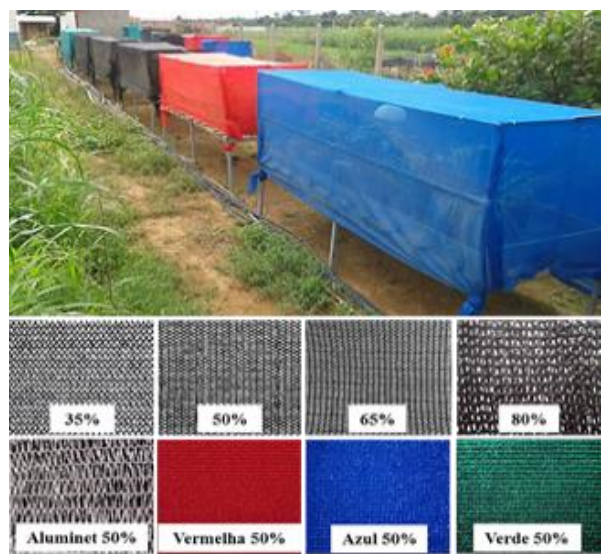

Figura 2. Viveiros suspensos com telas agrícolas poliefinas e a pleno sol, em Sinop-MT.

Figure 2. Suspended nurseries with poliefine screens and in full sun, in Sinop-MT.

\section{RESULTADOS}

\subsection{Dinâmica micrometeorológica de Tar e UR}

\subsubsection{Tar e UR em Pleno Sol}

Durante o período avaliado, na região de estudo ocorreram temperatura e umidade relativa do ar média anual de $26,0{ }^{\circ} \mathrm{C}$ e $73,0 \%$. Foram registrados extremos de temperatura do ar de 40,1 e $9,7^{\circ} \mathrm{C}$, enquanto que para UR, os valores máximo e mínimo foram de 99,4 e 10,0\%, respectivamente. As maiores amplitudes térmicas ocorreram durante a estação seca, variando de 21,5 a $27,3{ }^{\circ} \mathrm{C}$ entre os valores máximos e mínimos (Figura $3 \mathrm{~A}$ ). Para a umidade relativa do ar as maiores amplitudes foram de 78,0 a 88,0\% também na estação seca (Figura 3B). Os valores médios anuais da radiação global e insolação foram de $16,8 \mathrm{MJ} \mathrm{m}^{-2}$ $\operatorname{dia}^{-1}$ e 6,7 horas dia $^{-1}$.

\subsubsection{Tar e UR sob telas poliefinas pretas}

Observou-se dinâmica semelhante à condição de pleno sol na sazonalidade de Tar e UR nos ambientes com telas poliefinas pretas com 35, 50, 65 e $80 \%$ de sombreamento (Figuras 4 e 5). No entanto, quando comparado a condição de pleno sol, houve para temperatura do ar acréscimo expressivo nos valores máximos e médios e decréscimo nos mínimos, enquanto para umidade relativa do ar registrou-se aumento notável nos valores médios e mínimos.

Foram registrados no interior das telas de sombreamentos valores de Tar média de 26,4 e $26,0^{\circ} \mathrm{C}$ nas estações chuvosa e seca, respectivamente (Figuras 4E e 4H). O aumento no nível de sombreamento acarretou acréscimo de até $2,0 \%$ na UR média diária, com variações entre 82,0 e $84,0 \%$ na estação chuvosa e de 60,0 e $62,0 \%$ na estação seca (Figura 5E e 5H).

Para essa mesma região de estudo, Sabino et al. (2020) verificaram entre julho/2015 a abril/2016, valores médios diários de Tar e UR próximos de $26,0{ }^{\circ} \mathrm{C}$ e $90,0 \%$ nas telas pretas de 35, 50, 65 e $80 \%$ de sombreamento, indicando ainda uma redução de Tar e aumento de UR com relação ao pleno sol.

$\mathrm{Na}$ estação seca ocorreram maiores flutuações nos valores de Tar máxima e mínima diária, atingindo como valores extremos $45,6^{\circ} \mathrm{C}$ (às $15: 00 \mathrm{~h}$ em julho) e $45,8^{\circ} \mathrm{C}$ (às 12:00 h em agosto), e 9,3 a 9,7 ${ }^{\circ} \mathrm{C}$ (ambas às 05:00 h em julho), para as telas poliefinas pretas com 50 e $80 \%$ de sombreamento, respectivamente (Figura 4D-4I). Em contrapartida, constatou-se menor amplitude entre os valores máximos e mínimos de UR nesses ambientes protegidos, atingindo $100,0 \%$ no período noturno durante a estação chuvosa e $20,0 \%$ entre às 12:00 e 13:00 h na estação seca da região (Figura 5D- 5I).
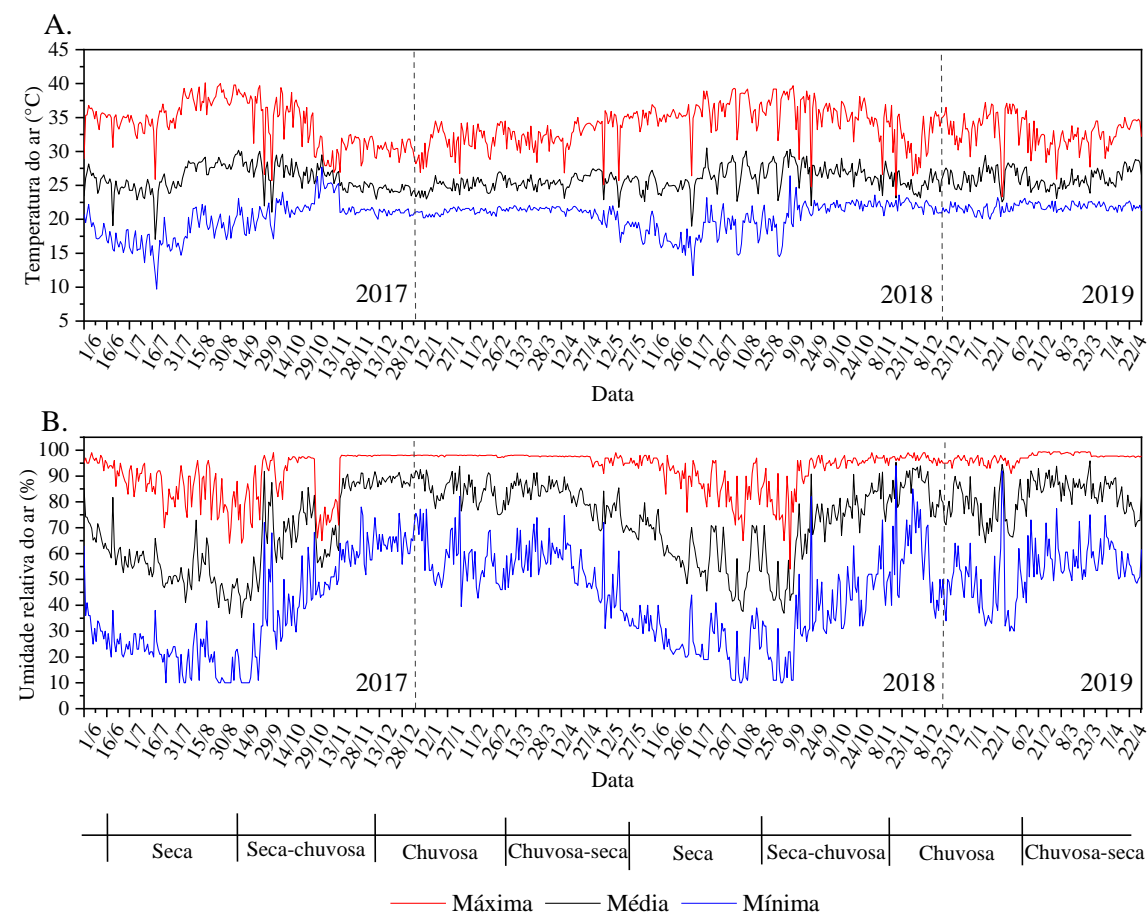

Figura 3. Temperatura do ar (A) e umidade relativa do ar (B) máxima, média e mínima diária, em Sinop-MT, entre 01/06/2017 e 30/04/2019. Figure 3. Air temperature (A) and relative humidity (B) maximum, mean and minimum daily, in Sinop-MT, between 06/01/2017 and $04 / 30 / 2019$. 


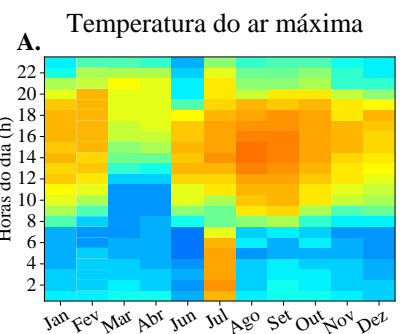

D.

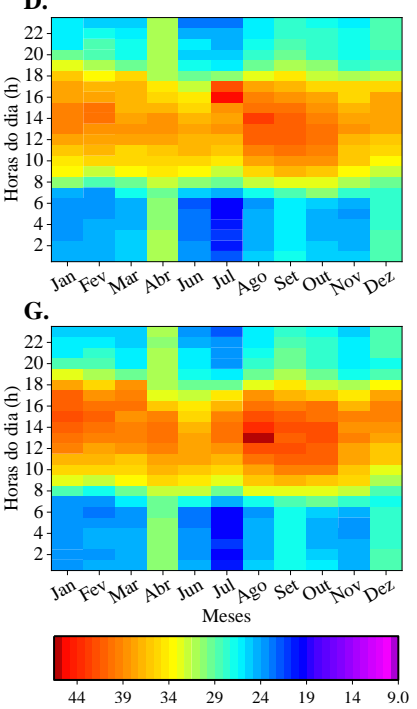

Temperatura do ar média

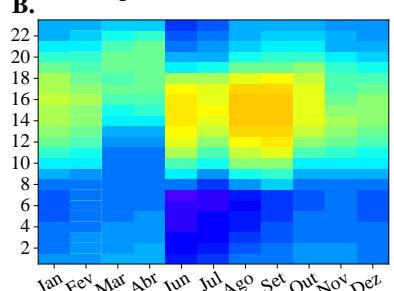

E.

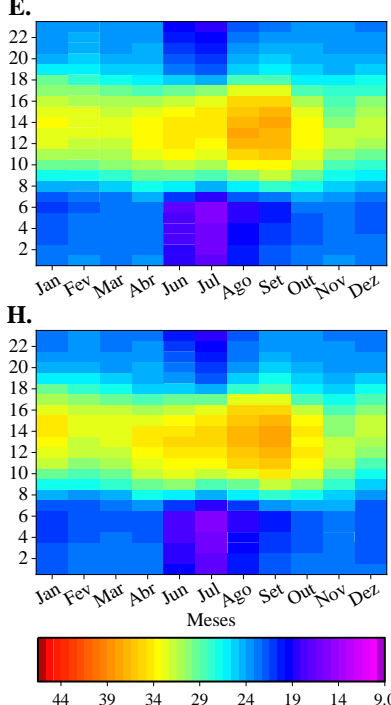

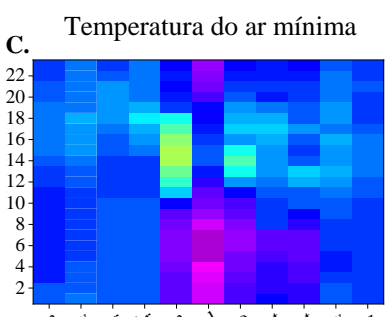

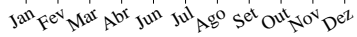

F.

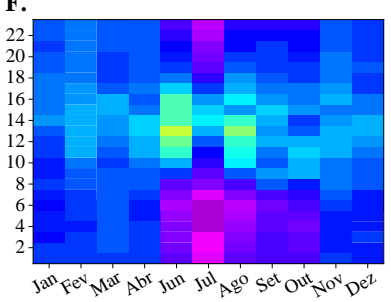

I.

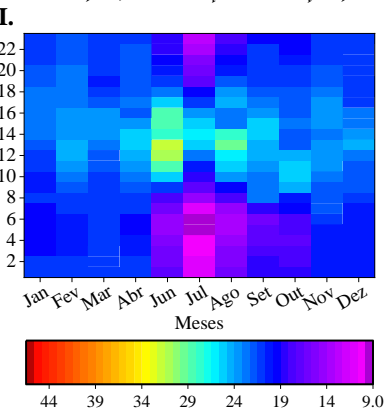

Figura 4. Dinâmica da temperatura do ar máxima, média e mínima diária ao longo do ano, em condições de pleno sol (A-B-C) e sob telas poliefinas pretas de 50\% (D-E-F) e 80\% (G-H-I), entre 04/06/2017 e 30/04/2019, em Sinop-MT.

Figure 4. Dynamic of the maximum, mean and minimum daily temperature throughout the year, in full sun conditions (A-B-C) and under black poliefins screens at 50\% (D-E-F) and 80\% (G-H-I), between 06/04/2017 and 04/30/2019, in Sinop-MT.

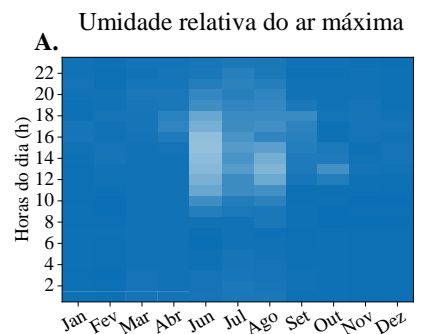

D.
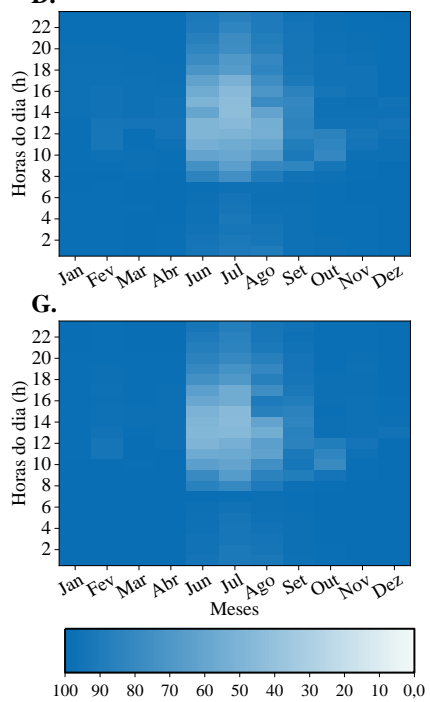

Umidade relativa do ar média
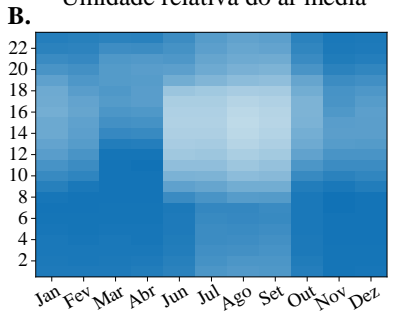

E.

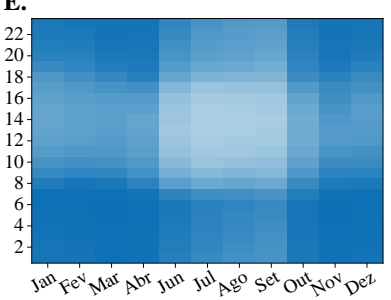

H.

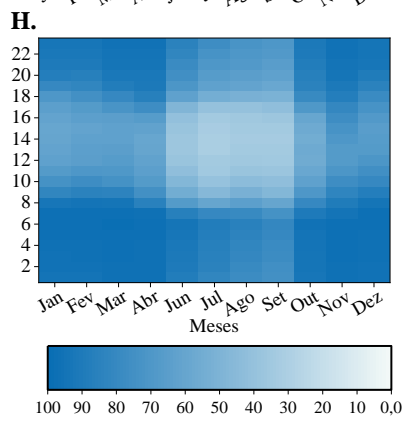

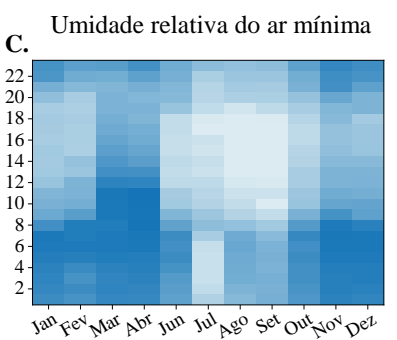

F.

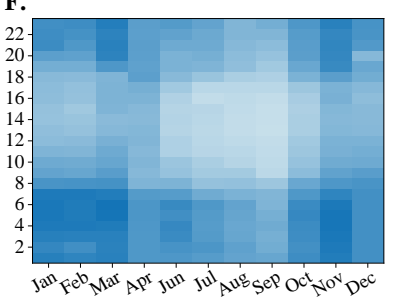

I.

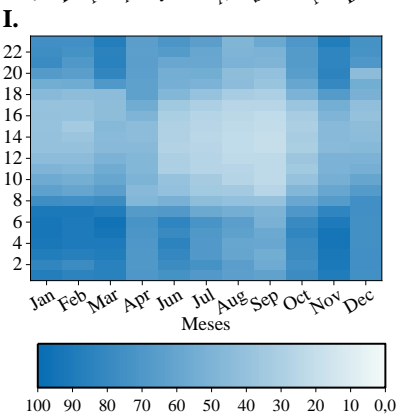

Figura 5. Dinâmica da umidade relativa do ar máxima, média e mínima diária ao longo do ano em condições de pleno sol (A-B-C) e sob telas poliefinas pretas de 50\% (D-E-F) e 80\% (G-H-I), entre 04/06/2017 e 30/04/2019, em Sinop-MT.

Figure 5. Dynamic of the maximum, mean and minimum daily air relative humidity throughout the year, in full sun (A-B-C) conditions and under black poliefins screens of 50\% (D-E-F) and 80\% (G-H-I), between 06/04/2017 and 30 / 04/2019, in Sinop-MT. 


\subsubsection{Tar e UR sob telas poliefinas coloridas}

Registrou-se valores médios diários de Tar de 26,7 $\pm 0,1$ ${ }^{\circ} \mathrm{C}$ e UR de $62,0 \pm 0,3 \%$ no interior das telas poliefinas termorefletora, vermelha, azul e verde durante a estação seca (junho-setembro/2017), sem diferenças significativas entre as condições de sombreamento (Figuras 6 e 7). Esses valores foram superiores aos registrados na tela poliefina preta $(50 \%$ de sombreamento), que gerou médias diárias de $26,0{ }^{\circ} \mathrm{C}$ e $61,0 \%$, e na condição de pleno sol com médias de $26,2{ }^{\circ} \mathrm{C}$ e $58,0 \%$.

Sabino et al. (2020) encontraram para essas mesmas telas de sombreamento, valores médios de Tar e UR de $25,3{ }^{\circ} \mathrm{C}$ e $85,6 \%$ sob tela azul; enquanto que para as demais telas, a Tar média foi $27,0^{\circ} \mathrm{C}$ e a UR média variou de $81,4,81,2$ e $82,2 \%$ sob telas vermelha, verde e termorefletora, respectivamente. Contudo, ressalta-se que os resultados obtidos nas telas coloridas por Sabino et al. (2020) abrangeram as estações seca e chuvosa do ano na região, enquanto que o presente trabalho avaliou apenas a estação seca.

Os meses de agosto e setembro apresentaram temperaturas máximas de $40,1^{\circ} \mathrm{C}$ (às $14: 00 \mathrm{~h}$ ) na condição de pleno sol, e ainda, 41,2; 50,2; 48,9; 47,1 e 46,0 ${ }^{\circ} \mathrm{C}$ (entre às 12:00 e 13:00 h) nas telas poliefinas preta 50\%, termorefletora, vermelha, azul e verde, respectivamente (Figura 6). A umidade relativa do ar mínima chegou a 10,0\% (das 12:00 às 17:00 h) na condição de pleno sol, e 18,0\% \pm $1,0 \%$ (das 12:00 às 13:00 h) nas telas poliefinas coloridas (Figura 7).
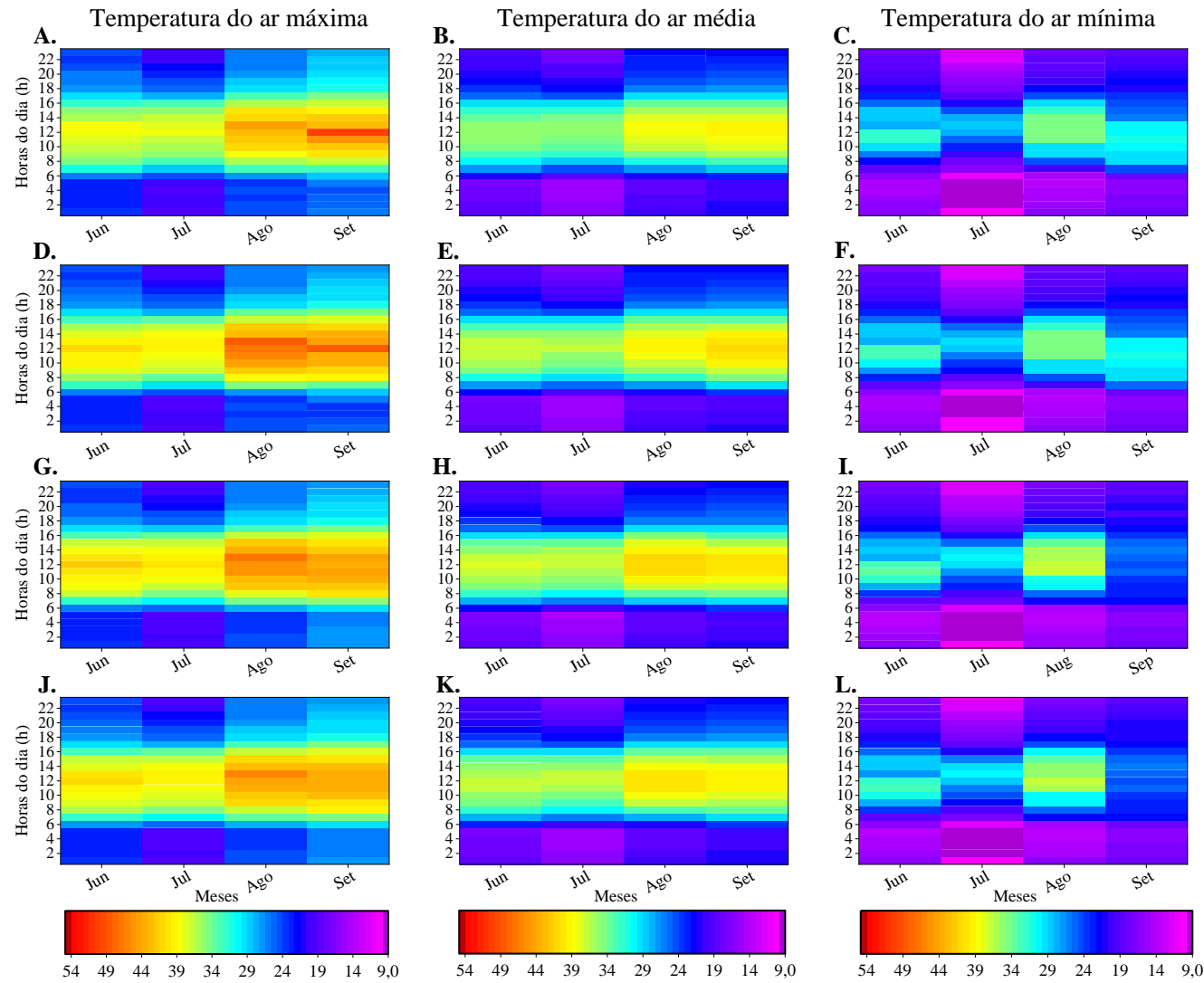

Figura 6. Dinâmica da temperatura do ar máxima, média e mínima diária ao longo do ano, em condições de sombreamento com telas poliefinas aluminet 50\% (A-B-C), chromatinet vermelha 50\% (D-E-F), chromatinet azul 50\% (G-H-I) e frontinet verde 50\% (J-K-L), entre 04/06/2017 e 30/09/2017, em Sinop-MT.

Figure 6. Dynamic of the maximum, mean and minimum daily temperature throughout the year, in shadowing to colours poliefins screens aluminet 50\% (A-B-C), chromatinet red 50\% (D-E-F), chromatinet blue 50\% (G-H-I) e frontinet green 50\% (J-K-L), between 06/04/2017 and 09/30/2017, in Sinop-MT.

\subsection{Medidas e estimativas de Tar e UR sob telas poliefinas pretas e coloridas}

Independentemente da tela de sombreamento, as maiores e menores amplitudes de Tar e UR ocorreram na estação seca com $20,0^{\circ} \mathrm{C}$ e $60,0 \%$, e na transição das estações chuvosaseca com $11,0{ }^{\circ} \mathrm{C}$ e $36,0 \%$, respectivamente (Figuras 8 e 9).

$\mathrm{Na}$ estação seca, as maiores amplitudes térmicas foram dependentes de forma mais expressa da diminuição de Tmín (temperatura mínima diária), quando comparado com o crescimento de Tmáx (temperatura máxima diária). As médias diárias (considerando a estação seca) de Tar foi de 25,0 ${ }^{\circ} \mathrm{C}$ sob pleno sol e telas poliefinas pretas de sombreamento, contudo, menores quando comparado com a estação chuvosa e transição chuvosa-seca. $\mathrm{Na}$ estação chuvosa, a Tar média se manteve mais elevada e constante $\left(27,0^{\circ} \mathrm{C}\right)$ em todas as telas de sombreamento e na condição de pleno sol. Esse comportamento, decorre da presença de vapor d'água na atmosfera, que desempenha um papel de condicionador térmico do ar, absorvendo boa parte da radiação em ondas curtas (diminuindo a transmissividade atmosférica) e aumenta a incidência de radiação em ondas longas atmosféricas (SANTOS et al., 2013), que condicionam a elevação da temperatura do ar.

Os valores dos desvios padrões (linhas vermelhas) indicam a variabilidade dos valores máximos, médios e mínimos diários de Tar e UR, especificamente para cada estação hídrica avaliada. Os valores estimados (marcadores "pontos" pretos) se aproximaram dos valores medidos nas 
telas poliefinas pretas de sombreamento em todas as estações hídricas do ano, exceto para Tmáx (Figura 8D) e URmín (Figura 9D) na transição chuvosa-seca.

Os menores valores médios de UR ocorreram na estação seca, entre 50,0 a 60,0\%, com mínimas observadas inferiores a $35,0 \%$, enquanto que, na estação chuvosa e nas transições (seca-chuvosa e chuvosa-seca), a UR média foi superior a $70,0 \%$, independentemente da condição de sombreamento.

Em geral, as diferenças entre os valores observados e estimados de Tar e UR nas telas coloridas com 50,0\% de sombreamento foram próximas, não ultrapassando de $0,4{ }^{\circ} \mathrm{C}$ e $1 \%$, nessa ordem (Figura 10).
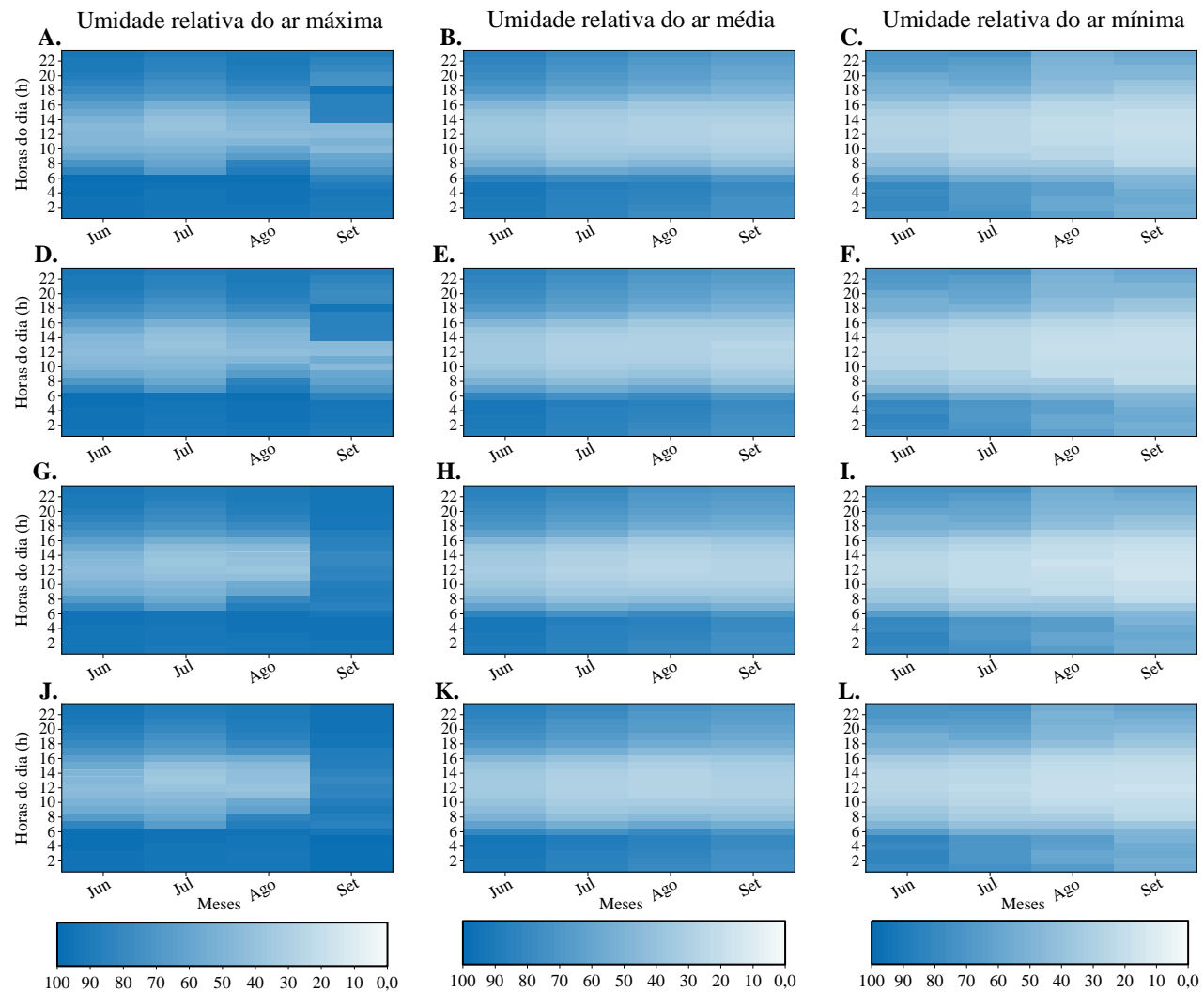

Figura 7. Dinâmica da umidade relativa do ar máxima, média e mínima diária ao longo do ano, em condições de sombreamento com telas poliefinas aluminet 50\% (A-B-C), chromatinet vermelha 50\% (D-E-F), chromatinet azul 50\% (G-H-I) e frontinet verde $50 \%$ (J-K-L), entre 04/06/2017 e 30/09/2017, em Sinop-MT.

Figure 7. Dynamic of the maximum, mean and minimum daily relative humidity throughout the year, in shadowing to colours poliefins screens aluminet 50\% (A-B-C), chromatinet red 50\% (D-E-F), chromatinet blue 50\% (G-H-I) e frontinet green $50 \%$ (J-K-L), between 06/04/2017 and 09/30/2017, in Sinop-MT.
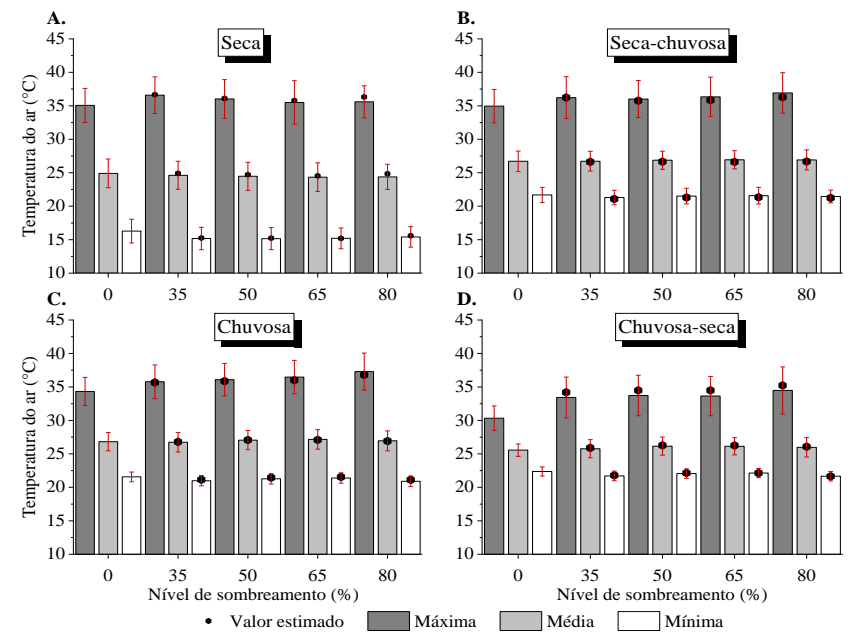

Figura 8. Temperatura do ar máxima, média e mínima observada e estimada sob diferentes telas poliefinas pretas e pleno sol, em diferentes estações hídricas do ano, entre 04/06/2017 e 30/04/2019, em Sinop-MT.

Figure 8. Maximum, mean and minimum air temperature observed and estimated under different black poliefins screens and full sun, in different water seasons of the year, between 06/04/2017 and 04/30/2019, in Sinop-MT.
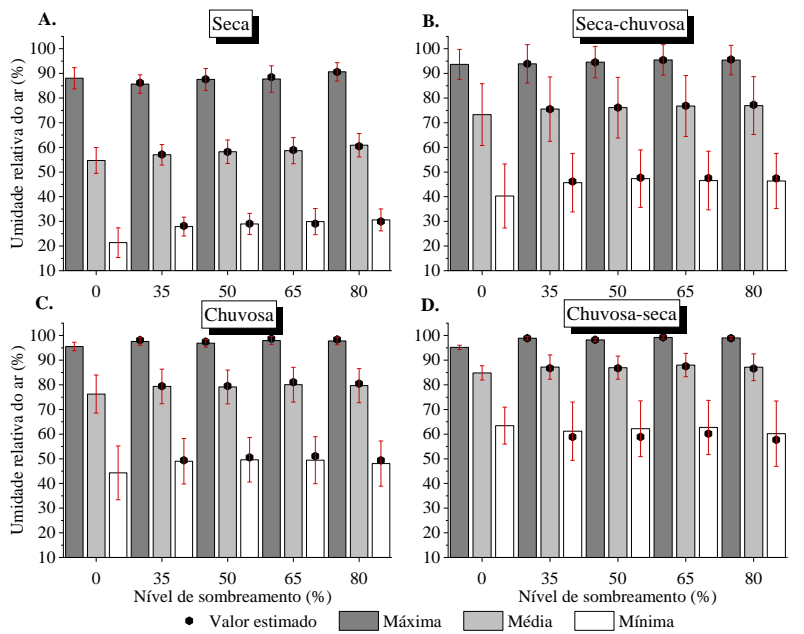

Figura 9. Umidade relativa do ar máxima, média e mínima observada e estimada sob diferentes telas poliefinas pretas e pleno sol, em diferentes estações hídricas do ano, entre 04/06/2017 e 30/04/2019, em Sinop-MT.

Figure 9. Maximum, mean and minimum relative humidity observed and estimated under different black poliefins screens and full sun, in different water seasons of the year, between 06/04/2017 and 04/30/2019, in Sinop-MT. 

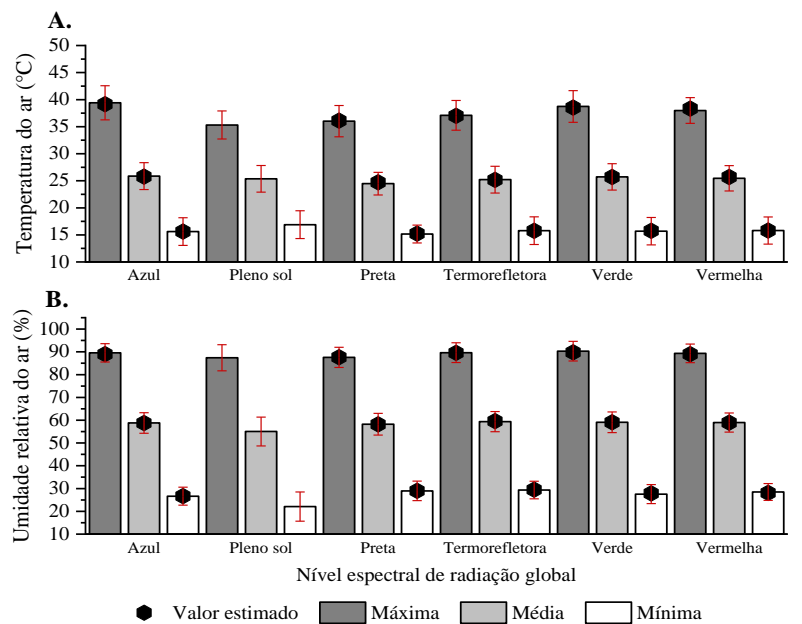

Figura 10. Temperatura e umidade relativa do ar máxima, média e mínima observada e estimada sob diferentes telas poliefinas coloridas, preta $50 \%$ e pleno sol, na estação seca, em Sinop-MT.

Figure 10. Maximum, mean and minimum air temperature and relative humidity observed and estimated under different colours poliefins screens, black $50 \%$ and full sun, in dry season, in SinopMT.
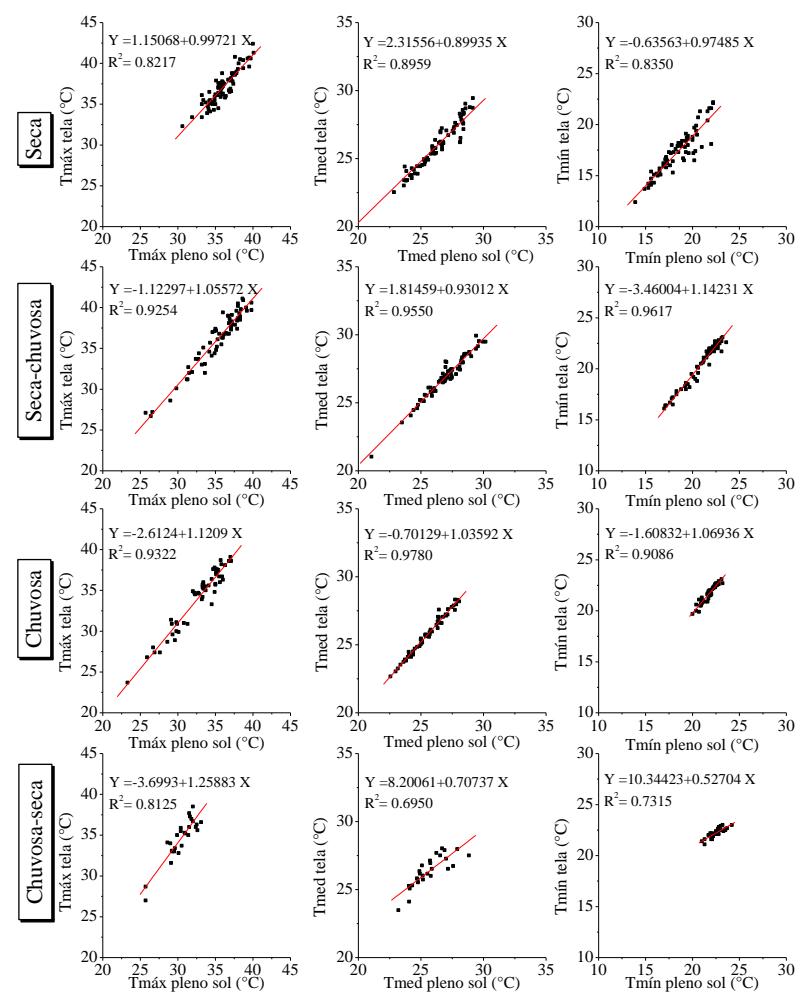

Figura 11. Equações lineares de estimativas da temperatura máxima (Tmáx), média (Tméd) e mínima (Tmín), sob tela poliefina preta 50\%, em diferentes estações hídricas do ano, em Sinop-MT. (As mesmas variáveis em pleno Sol correspondem a " $X$ ")

Figure 11. Linear equations for estimatives for maximum (Tmax), mean (Tmed) and minimum (Tmin) air temperature, under 50\% black poliefins screen, in different water conditions of the year, in Sinop-MT. (The same variables in full sun correspond to " $X "$ )

\subsection{Equações estatísticas de estimativas de Tar e UR}

Foram ajustadas regressões lineares simplificadas baseadas na condição pleno sol como referência, visto que o seu monitoramento de rotina é realizado com mais facilidade em diversas regiões brasileiras. Além disso, visando aplicações em pesquisas agrícolas e ambientais regionais, as regressões foram ajustadas em condições físico-hídricas distintas baseadas no regime hídrico da região (seca, secachuvosa, chuvosa, chuvosa-seca). Observou-se regressões crescentes, independente da estação hídrica do ano (Figuras 11 e 12 , e Tabelas 1 e 2).

Os coeficientes de determinação $\left(\mathrm{R}^{2}\right)$ das regressões ajustadas para Tar variaram de 62 a $90 \%$ e de 89 a $98 \%$ nas estações seca e chuvosa; de 89 a $97 \%$ e de 65 a $83 \%$ nas transições seca-chuvosa e chuvosa-seca, respectivamente (Tabela 1). Em geral, os valores de $\mathrm{R}^{2}$ indicam que mais de $60 \%$ da variável dependente (temperatura do ar nas telas de sombreamento) está relacionada à variável independente (temperatura do ar na condição de pleno sol).

Os valores de $\mathrm{MBE}$ variaram de $-0,003$ a $0,73^{\circ} \mathrm{C}$ na seca; de $-0,63$ a $0,02{ }^{\circ} \mathrm{C}$ na seca-chuvosa; de $-0,49$ a $0,22{ }^{\circ} \mathrm{C}$ na chuvosa e de $-0,02$ a $0,84{ }^{\circ} \mathrm{C}$ na chuvosa-seca; sendo que as maiores subestimativas ocorreram na transição seca-chuvosa e na estação chuvosa. Os espalhamentos (RMSE) variaram de 0,31 a $1,04{ }^{\circ} \mathrm{C} ; 0,38$ a $1,08{ }^{\circ} \mathrm{C} ; 0,18$ a $1,12{ }^{\circ} \mathrm{C}$ e 0,35 a 1,39 ${ }^{\circ} \mathrm{C}$ nas estações seca, seca-chuvosa, chuvosa e chuvosa-seca, respectivamente (Tabela 1 )
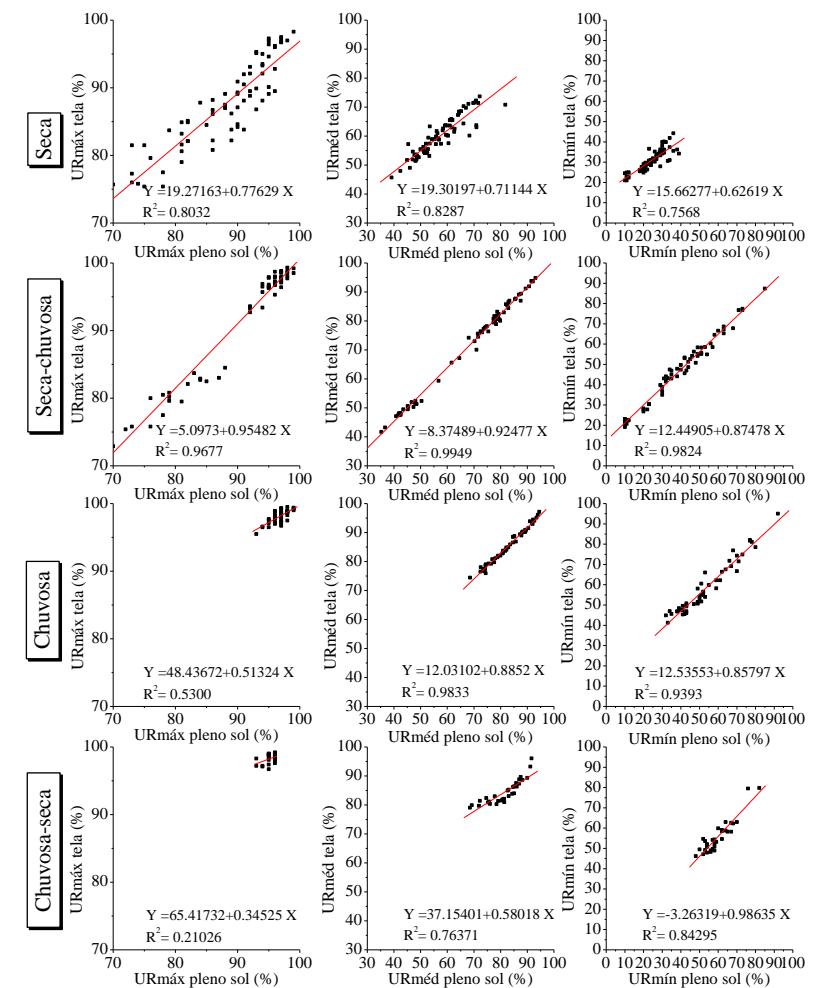

Figura 12. Equações lineares de estimativas da umidade relativa do ar máxima (URmáx), média (URméd) e mínima (URmín), sob tela poliefina preta $50 \%$, em diferentes estações hídricas do ano, em Sinop-MT. (As mesmas variáveis em pleno Sol correspondem a " $X^{\prime \prime}$ )

Figure 12. Linear equations for estimatives for maximum (URmax), mean (URmed) and minimum (URmin) relative humidity, under $50 \%$ black poliefins screen, in different water conditions of the year, in Sinop-MT. (The same variables in full sun correspond to " $X$ ") 
Tabela 1. Equações de estimativas da temperatura e umidade relativa do ar (máxima, média e mínima) em diferentes condições de sombreamento e estações hídricas do ano, em Sinop-MT.

Table 1. Equations for estimating air temperature and relative humidity (maximum, mean and minimum) under different shading conditions and water seasons of the year, in Sinop-MT.

\begin{tabular}{|c|c|c|c|c|c|c|c|}
\hline Estação Hídrica & Telas & Variáveis & Equações lineares & $\mathrm{R}^{2}$ & $\mathrm{MBE}$ & RMSE & $\mathrm{d}$ \\
\hline \multirow{24}{*}{$\begin{array}{l}\tilde{U} \\
\ddot{n}\end{array}$} & \multirow{3}{*}{ Preta $35,0 \%$} & Tmáx & $Y=2,65647+0,97016 X$ & 0,791 & 0,0856 & 0,6686 & 0,9983 \\
\hline & & Tméd & $Y=2,8984+0,88355 X$ & 0,901 & 0,2876 & 0,3885 & 0,9990 \\
\hline & & Tmín & $Y=-0,52986+0,9697 X$ & 0,836 & 0,0848 & 0,3138 & 0,9994 \\
\hline & \multirow{3}{*}{ Preta $50,0 \%$} & Tmáx & $Y=1,15068+0,99721 X$ & 0,822 & 0,0888 & 0,7360 & 0,9983 \\
\hline & & Tméd & $Y=2,31556+0,89935 X$ & 0,896 & 0,2492 & 0,3846 & 0,9991 \\
\hline & & Tmín & $Y=-0,63563+0,97485 X$ & 0,835 & 0,0696 & 0,3500 & 0,9992 \\
\hline & \multirow{3}{*}{ Preta $65,0 \%$} & Tmáx & $Y=-1,22747+1,05608 X$ & 0,767 & 0,2916 & 0,9528 & 0,9977 \\
\hline & & Tméd & $\mathrm{Y}=1,1144+0,94004 \mathrm{X}$ & 0,890 & 0,1856 & 0,3783 & 0,9992 \\
\hline & & Tmín & $Y=-0,61268+0,97133 X$ & 0,832 & $-0,0028$ & 0,5237 & 0,9981 \\
\hline & \multirow{3}{*}{ Preta $80,0 \%$} & Tmáx & $Y=4,76694+0,90021 X$ & 0,625 & 0,7284 & 10,4390 & 0,9959 \\
\hline & & Tméd & $Y=3,87622+0,84182 X$ & 0,864 & 0,4600 & 0,5294 & 0,9981 \\
\hline & & Tmín & $\mathrm{Y}=1,07775+0,89239 \mathrm{X}$ & 0,741 & 0,1904 & 0,4707 & 0,9985 \\
\hline & \multirow{3}{*}{ Preta $35,0 \%$} & URmáx & $Y=18,96244+0,76384 X$ & 0,818 & 0,5592 & 16,2900 & 0,9965 \\
\hline & & URméd & $Y=18,23695+0,71164 X$ & 0,853 & 0,1532 & 0,9119 & 0,9991 \\
\hline & & URmín & $\mathrm{Y}=15,32479+0,60092 \mathrm{X}$ & 0,738 & 0,2568 & 12,9200 & 0,9975 \\
\hline & \multirow{3}{*}{ Preta $50,0 \%$} & URmáx & $Y=19,27163+0,77629 X$ & 0,803 & 0,0600 & 24,0810 & 0,9939 \\
\hline & & URméd & $Y=19,30197+0,71144 X$ & 0,829 & $-0,0184$ & 16,0860 & 0,9976 \\
\hline & & URmín & $\mathrm{Y}=15,66277+0,62619 \mathrm{X}$ & 0,757 & 0,0704 & 13,4660 & 0,9976 \\
\hline & \multirow{3}{*}{ Preta $65,0 \%$} & URmáx & $\mathrm{Y}=19,82136+0,77998 \mathrm{X}$ & 0,738 & 0,7712 & 36,7670 & 0,9900 \\
\hline & & URméd & $Y=19,82095+0,71513 X$ & 0,789 & 0,2440 & 21,3990 & 0,9965 \\
\hline & & URmín & $Y=15,9054+0,61725 X$ & 0,702 & $-0,8268$ & 24,7150 & 0,9935 \\
\hline & \multirow{3}{*}{ Preta $80,0 \%$} & URmáx & $Y=31,01001+0,67677 X$ & 0,794 & $-0,0708$ & 19,8170 & 0,9940 \\
\hline & & URméd & $Y=24,17127+0,66366 X$ & 0,806 & $-0,4304$ & 17,8870 & 0,9969 \\
\hline & & URmín & $\mathrm{Y}=17,11135+0,60171 \mathrm{X}$ & 0,698 & $-0,6348$ & 15,7520 & 0,9967 \\
\hline \multirow{24}{*}{ 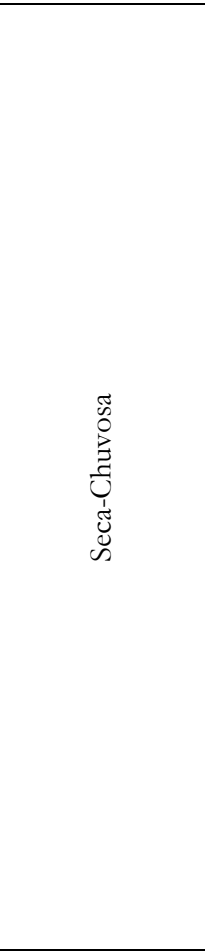 } & \multirow{3}{*}{ Preta $35,0 \%$} & Tmáx & $Y=-4,30091+1,16002 X$ & 0,909 & 0,0235 & 10,4160 & 0,9975 \\
\hline & & Tméd & $Y=-1,05793+1,0365 X$ & 0,970 & $-0,0977$ & 0,4209 & 0,9985 \\
\hline & & Tmín & $Y=-2,17719+1,07293 X$ & 0,973 & $-0,2188$ & 0,3977 & 0,9976 \\
\hline & \multirow{3}{*}{ Preta $50,0 \%$} & Tmáx & $Y=-1,12297+1,05572 X$ & 0,925 & $-0,2335$ & 0,8702 & 0,9979 \\
\hline & & Tméd & $Y=1,81459+0,93012 X$ & 0,955 & $-0,2058$ & 0,3816 & 0,9985 \\
\hline & & Tmín & $Y=-3,46004+1,14231 X$ & 0,962 & $-0,2100$ & 0,4120 & 0,9977 \\
\hline & \multirow{3}{*}{ Preta $65,0 \%$} & Tmáx & $Y=-1,57702+1,07072 X$ & 0,888 & $-0,4973$ & 10,7870 & 0,9970 \\
\hline & & Tméd & $Y=2,69599+0,89591 X$ & 0,919 & $-0,3031$ & 0,4479 & 0,9980 \\
\hline & & Tmín & $Y=-4,24586+1,18009 X$ & 0,953 & $-0,2385$ & 0,4139 & 0,9980 \\
\hline & \multirow{3}{*}{ Preta $80,0 \%$} & Tmáx & $Y=-3,64833+1,14296 X$ & 0,887 & $-0,6281$ & 10,7700 & 0,9973 \\
\hline & & Tméd & $Y=0,58039+0,97728 X$ & 0,944 & $-0,2296$ & 0,5341 & 0,9977 \\
\hline & & Tmín & $Y=-0,65502+1,00966 X$ & 0,953 & $-0,2154$ & 0,4359 & 0,9966 \\
\hline & \multirow{3}{*}{ Preta $35,0 \%$} & URmáx & $Y=-4,44846+1,0505 X$ & 0,918 & 0,0662 & 31,4360 & 0,9965 \\
\hline & & URméd & $Y=5,22529+0,95886 X$ & 0,990 & $-0,0281$ & 16,8340 & 0,9997 \\
\hline & & URmín & $Y=10,64328+0,88114 X$ & 0,979 & 0,4912 & 32,4410 & 0,9989 \\
\hline & \multirow{3}{*}{ Preta $50,0 \%$} & URmáx & $\mathrm{Y}=5,0973+0,95482 \mathrm{X}$ & 0,968 & $-0,0727$ & 12,9480 & 0,9990 \\
\hline & & URméd & $Y=8,37489+0,92477 X$ & 0,995 & 0,0242 & 12,9010 & 0,9998 \\
\hline & & URmín & $Y=12,44905+0,87478 X$ & 0,982 & 0,3719 & 25,6580 & 0,9993 \\
\hline & \multirow{3}{*}{ Preta $65,0 \%$} & URmáx & $Y=10,97043+0,90179 X$ & 0,963 & $-0,0312$ & 12,6220 & 0,9990 \\
\hline & & URméd & $Y=9,44871+0,91982 X$ & 0,994 & 0,0827 & 13,7440 & 0,9998 \\
\hline & & URmín & $Y=11,21279+0,90188 X$ & 0,983 & 10,023 & 27,4040 & 0,9992 \\
\hline & \multirow{3}{*}{ Preta $80,0 \%$} & URmáx & $Y=19,73537+0,81057 X$ & 0,939 & 0,2292 & 16,2840 & 0,9982 \\
\hline & & URméd & $Y=13,31271+0,87239 X$ & 0,992 & 0,3058 & 13,6280 & 0,9998 \\
\hline & & URmín & $\mathrm{Y}=12,37236+0,86965 \mathrm{X}$ & 0,978 & 10,454 & 26,1720 & 0,9992 \\
\hline
\end{tabular}

em que: Tmáx, Tméd e Tmín são as temperaturas máximas, médias e mínimas diárias (em $\left.{ }^{\circ} \mathrm{C}\right)$; URmáx, URméd e URmín são as umidades relativa do ar máxima, média e mínima diárias (em \%), respectivamente; $\mathrm{R}^{2}$ é o coeficiente de determinação; MBE e RMSE são o erro quadrado médio e a raiz quadrática do erro quadrático médio (em ${ }^{\circ} \mathrm{C}$ para Tar e \% para UR); “d” é o índice de ajustamento de Willmott. Nas regressões lineares "X” representa as mesmas variáveis obtidas na condição de pleno sol. 
Tabela 1. Equações de estimativas da temperatura e umidade relativa do ar (máxima, média e mínima) ... CONTINUAÇÃO Table 1. Equations for estimating air temperature and relative humidity (maximum, mean and minimum) ... CONTINUATION

\begin{tabular}{|c|c|c|c|c|c|c|c|}
\hline Estação Hídrica & Telas & Variáveis & Equações lineares & $\mathrm{R}^{2}$ & $\mathrm{MBE}$ & RMSE & $\mathrm{d}$ \\
\hline \multirow{24}{*}{$\begin{array}{l}\tilde{B} \\
0 \\
\vdots \\
己 \\
\text { Uु }\end{array}$} & \multirow{3}{*}{ Preta $35,0 \%$} & Tmáx & $Y=-4,20903+1,1621 X$ & 0,938 & $-0,0964$ & 0,8086 & 0,9984 \\
\hline & & Tméd & $Y=-1,64473+1,06104 X$ & 0,980 & 0,0596 & 0,2263 & 0,9997 \\
\hline & & Tmín & $Y=-1,57304+1,05325 X$ & 0,927 & 0,1472 & 0,3003 & 0,9979 \\
\hline & \multirow{3}{*}{ Preta $50,0 \%$} & Tmáx & $\mathrm{Y}=-2,6124+1,1209 \mathrm{X}$ & 0,932 & $-0,2264$ & 0,8193 & 0,9983 \\
\hline & & Tméd & $Y=-0,70129+1,03592 X$ & 0,978 & 0,0168 & 0,1824 & 0,9998 \\
\hline & & Tmín & $Y=-1,60832+1,06936 X$ & 0,909 & 0,1784 & 0,3298 & 0,9975 \\
\hline & \multirow{3}{*}{ Preta $65,0 \%$} & Tmáx & $Y=-3,37431+1,14716 X$ & 0,926 & $-0,4756$ & 0,9297 & 0,9979 \\
\hline & & Tméd & $Y=-0,33665+1,02326 X$ & 0,975 & $-0,0628$ & 0,2152 & 0,9997 \\
\hline & & Tmín & $Y=-1,75421+1,08049 X$ & 0,919 & 0,1444 & 0,3215 & 0,9976 \\
\hline & \multirow{3}{*}{ Preta $80,0 \%$} & Tmáx & $Y=-5,99624+1,24703 X$ & 0,918 & $-0,4856$ & 11,2330 & 0,9975 \\
\hline & & Tméd & $Y=-1,67922+1,06665 X$ & 0,965 & $-0,0248$ & 0,2694 & 0,9995 \\
\hline & & Tmín & $Y=-1,11014+1,03101 X$ & 0,894 & 0,2196 & 0,3613 & 0,9969 \\
\hline & \multirow{3}{*}{ Preta $35,0 \%$} & URmáx & $Y=48,34581+0,52142 X$ & 0,512 & 0,5636 & 10,1310 & 0,9880 \\
\hline & & URméd & $Y=8,53038+0,93046 X$ & 0,983 & 0,1423 & 0,7652 & 0,9998 \\
\hline & & URmín & $\mathrm{Y}=9,2585+0,90623 \mathrm{X}$ & 0,949 & 0,4023 & 17,8310 & 0,9994 \\
\hline & \multirow{3}{*}{ Preta $50,0 \%$} & URmáx & $Y=48,43672+0,51324 X$ & 0,530 & 0,5873 & 0,9982 & 0,9883 \\
\hline & & URméd & $Y=12,03102+0,8852 X$ & 0,983 & 0,4077 & 0,8757 & 0,9997 \\
\hline & & URmín & $\mathrm{Y}=12,53553+0,85797 \mathrm{X}$ & 0,939 & 0,9273 & 17,9380 & 0,9994 \\
\hline & \multirow{3}{*}{ Preta $65,0 \%$} & URmáx & $Y=56,75795+0,43903 X$ & 0,551 & 0,7677 & 12,3570 & 0,9841 \\
\hline & & URméd & $Y=15,17189+0,86365 X$ & 0,973 & 0,9609 & 13,7380 & 0,9994 \\
\hline & & URmín & $\mathrm{Y}=12,12893+0,87973 \mathrm{X}$ & 0,945 & 16,445 & 23,4760 & 0,9990 \\
\hline & \multirow{3}{*}{ Preta $80,0 \%$} & URmáx & $Y=57,69386+0,42609 X$ & 0,543 & 0,6132 & 11,2430 & 0,9830 \\
\hline & & URméd & $Y=13,64548+0,87654 X$ & 0,967 & 0,8223 & 12,0380 & 0,9995 \\
\hline & & URmín & $Y=9,32647+0,90477 X$ & 0,949 & 13,373 & 23,6540 & 0,9990 \\
\hline \multirow{24}{*}{ 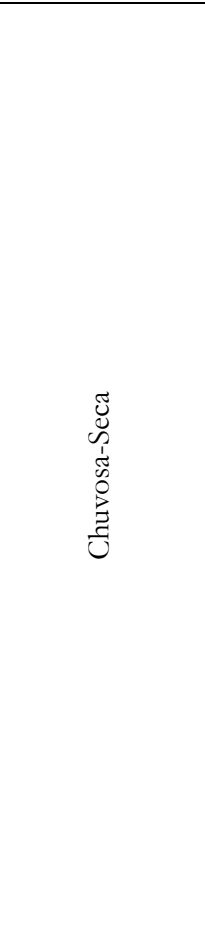 } & \multirow{3}{*}{ Preta $35,0 \%$} & Tmáx & $Y=-4,67908+1,28118 X$ & 0,813 & 0,7669 & 12,9340 & 0,9926 \\
\hline & & Tméd & $Y=7,44091+0,72259 X$ & 0,708 & 0,1392 & 0,7972 & 0,9801 \\
\hline & & Tmín & $Y=8,91486+0,57518 X$ & 0,733 & 0,0731 & 0,3869 & 0,9869 \\
\hline & \multirow{3}{*}{ Preta $50,0 \%$} & Tmáx & $Y=-3,6993+1,25883 X$ & 0,813 & 0,7700 & 13,9470 & 0,9912 \\
\hline & & Tméd & $Y=8,20061+0,70737 X$ & 0,695 & 0,1185 & 0,7760 & 0,9805 \\
\hline & & Tmín & $\mathrm{Y}=10,34423+0,52704 \mathrm{X}$ & 0,732 & 0,0799 & 0,3978 & 0,9853 \\
\hline & \multirow{3}{*}{ Preta $65,0 \%$} & Tmáx & $Y=-5,79628+1,32741 X$ & 0,804 & 0,8369 & 13,3210 & 0,9922 \\
\hline & & Tméd & $\mathrm{Y}=7,7636+0,72337 \mathrm{X}$ & 0,703 & 0,1169 & 0,7176 & 0,9828 \\
\hline & & Tmín & $\mathrm{Y}=9,48285+0,56576 \mathrm{X}$ & 0,740 & 0,0008 & 0,3451 & 0,9881 \\
\hline & \multirow{3}{*}{ Preta $80,0 \%$} & Tmáx & $Y=-7,12959+1,39644 X$ & 0,826 & 0,7585 & 13,9330 & 0,9932 \\
\hline & & Tméd & $Y=6,44111+0,76808 X$ & 0,679 & 0,0946 & 0,8613 & 0,9801 \\
\hline & & Tmín & $Y=10,15343+0,51349 X$ & 0,654 & $-0,0208$ & 0,4024 & 0,9836 \\
\hline & \multirow{3}{*}{ Preta $35,0 \%$} & URmáx & $Y=66,08547+0,34511 X$ & 0,217 & 0,0273 & 0,4755 & 0,9714 \\
\hline & & URméd & $Y=34,93409+0,61073 X$ & 0,771 & $-0,4618$ & 31,0900 & 0,9669 \\
\hline & & URmín & $Y=-9,19799+1,07297 X$ & 0,865 & $-23,309$ & 49,9820 & 0,9897 \\
\hline & \multirow{3}{*}{ Preta $50,0 \%$} & URmáx & $Y=65,41732+0,34525 X$ & 0,210 & 0,0336 & 0,3977 & 0,9755 \\
\hline & & URméd & $Y=37,15401+0,58018 X$ & 0,764 & $-0,2109$ & 28,3910 & 0,9697 \\
\hline & & URmín & $Y=-3,26319+0,98635 X$ & 0,843 & $-33,036$ & 51,4920 & 0,9895 \\
\hline & \multirow{3}{*}{ Preta $65,0 \%$} & URmáx & $Y=70,21006+0,30531 X$ & 0,179 & 0,0418 & 0,3904 & 0,9750 \\
\hline & & URméd & $Y=38,50593+0,57754 X$ & 0,741 & $-0,5273$ & 30,2980 & 0,9655 \\
\hline & & URmín & $Y=-6,56815+1,05259 X$ & 0,856 & $-24,945$ & 47,7350 & 0,9901 \\
\hline & \multirow{3}{*}{ Preta $80,0 \%$} & URmáx & $Y=74,98659+0,25126 X$ & 0,109 & $-0,0855$ & 0,4065 & 0,9612 \\
\hline & & URméd & $Y=35,40553+0,60407 X$ & 0,731 & $-0,4836$ & 35,7350 & 0,9625 \\
\hline & & URmín & $Y=-8,10229+1,03705 X$ & 0,835 & $-24,973$ & 62,5290 & 0,9863 \\
\hline
\end{tabular}

em que: Tmáx, Tméd e Tmín são as temperaturas máximas, médias e mínimas diárias (em $\left.{ }^{\circ} \mathrm{C}\right)$; URmáx, URméd e URmín são as umidades relativa do ar máxima, média e mínima diárias (em \%), respectivamente; $\mathrm{R}^{2}$ é o coeficiente de determinação; MBE e RMSE são o erro quadrado médio e a raiz quadrática do erro quadrático médio (em ${ }^{\circ} \mathrm{C}$ para Tar e \% para UR); “d” é o índice de ajustamento de Willmott. Nas regressões lineares "X" representa as mesmas variáveis obtidas na condição de pleno sol. 
Tabela 2. Equações de estimativas da temperatura e umidade relativa do ar (máxima, média e mínima) sob diferentes telas poliefinas coloridas na estação seca, em Sinop-MT.

Table 2. Equations for estimating air temperature and relative humidity (maximum, mean and minimum) under different colours poliefins screens in dry season, in Sinop-MT.

\begin{tabular}{|c|c|c|c|c|c|c|}
\hline Telas & Variáveis & Equações lineares & $\mathrm{R}^{2}$ & MBE & RMSE & $\mathrm{d}$ \\
\hline \multirow{3}{*}{ Termorefletora $50,0 \%$} & Tmáx & $\mathrm{Y}=2,90072+0,9662 \mathrm{X}$ & 0,8383 & $-0,1100$ & 0,9709 & 0,9982 \\
\hline & Tméd & $Y=-0,13929+0,99898 X$ & 0,9673 & $-0,0456$ & 0,4412 & 0,9995 \\
\hline & Tmín & $Y=-1,69668+1,04044 X$ & 0,9259 & $-0,0191$ & 0,4563 & 0,9996 \\
\hline \multirow{3}{*}{ Vermelha $50,0 \%$} & Tmáx & $Y=0,55982+1,07096 X$ & 0,7150 & 0,3626 & 1,1305 & 0,9970 \\
\hline & Tméd & $Y=14,58562+0,80978 X$ & 0,9800 & 0,2491 & 0,4825 & 0,9994 \\
\hline & Tmín & $Y=-1,49019+1,03006 X$ & 0,9215 & $-0,0097$ & 0,4881 & 0,9995 \\
\hline \multirow{3}{*}{ Azul 50,0\% } & Tmáx & $\mathrm{Y}=3,32856+1,01496 \mathrm{X}$ & 0,7824 & $-0,2612$ & 1,2564 & 0,9977 \\
\hline & Tméd & $Y=0,03608+1,01651 X$ & 0,9425 & $-0,0744$ & 0,5042 & 0,9994 \\
\hline & Tmín & $\mathrm{Y}=-2,0143+1,05114 \mathrm{X}$ & 0,9179 & 0,0085 & 0,4973 & 0,9995 \\
\hline \multirow{3}{*}{ Verde $50,0 \%$} & Tmáx & $\mathrm{Y}=4,88752+0,95335 \mathrm{X}$ & 0,7597 & $-0,2088$ & 1,0977 & 0,9979 \\
\hline & Tméd & $Y=0,72393+0,98625 X$ & 0,9495 & $-0,0297$ & 0,4594 & 0,9995 \\
\hline & Tmín & $Y=-1,55616+1,03121 X$ & 0,9140 & 0,0538 & 0,5215 & 0,9994 \\
\hline \multirow{3}{*}{ Termorefletora $50,0 \%$} & URmáx & $Y=24,16873+0,7453 X$ & 0,9228 & $-0,0975$ & 1,9256 & 0,9969 \\
\hline & URméd & $Y=14,51544+0,82321 X$ & 0,9808 & 0,2225 & 1,6808 & 0,9982 \\
\hline & URmín & $Y=13,79452+0,7306 X$ & 0,9220 & 0,1441 & 1,2147 & 0,9986 \\
\hline \multirow{3}{*}{ Vermelha $50,0 \%$} & URmáx & $Y=28,44125+0,69064 X$ & 0,9197 & $-0,3134$ & 1,7767 & 0,9969 \\
\hline & URméd & $Y=14,58562+0,80978 X$ & 0,9800 & $-0,0797$ & 1,4820 & 0,9984 \\
\hline & URmín & $\mathrm{Y}=13,10718+0,69831 \mathrm{X}$ & 0,9090 & $-0,3931$ & 1,4840 & 0,9977 \\
\hline \multirow{3}{*}{ Azul 50,0\% } & URmáx & $\mathrm{Y}=32,74801+0,64101 \mathrm{X}$ & 0,9078 & $-0,5772$ & 2,2714 & 0,9946 \\
\hline & URméd & $Y=14,77719+0,80284 X$ & 0,9697 & $-0,0597$ & 1,6649 & 0,9982 \\
\hline & URmín & $\mathrm{Y}=10,95874+0,73087 \mathrm{X}$ & 0,9230 & 0,0244 & 1,4499 & 0,9982 \\
\hline \multirow{3}{*}{ Verde $50,0 \%$} & URmáx & $\mathrm{Y}=28,32971+0,70054 \mathrm{X}$ & 0,9002 & $-0,5219$ & 2,2957 & 0,9955 \\
\hline & URméd & $Y=15,83333+0,79007 X$ & 0,9714 & $-0,0231$ & 1,5851 & 0,9984 \\
\hline & URmín & $\mathrm{Y}=13,63842+0,66231 \mathrm{X}$ & 0,8820 & 0,3213 & 1,3619 & 0,9983 \\
\hline
\end{tabular}

em que: Tmáx, Tméd e Tmín são as temperaturas máximas, médias e mínimas diárias (em $\left.{ }^{\circ} \mathrm{C}\right)$; URmáx, URméd e URmín são as umidades relativa do ar máxima, média e mínima diárias (em \%), respectivamente; $\mathrm{R}^{2}$ é o coeficiente de determinação; MBE e RMSE são o erro quadrado médio e a raiz quadrática do erro quadrático médio (em ${ }^{\circ} \mathrm{C}$ para Tar e \% para UR); "d" é o índice de ajustamento de Willmott. Nas regressões lineares "X" representa as mesmas variáveis obtidas na condição de pleno sol.

\section{DISCUSSÃO}

4.1. Dinâmica micrometeorológica de Tar e UR em pleno sol e nas condições de sombreamento

$\mathrm{Na}$ condição de pleno sol, os valores médios diários de Tar e UR foram iguais a $25,9^{\circ} \mathrm{C}$ e $81,0 \%$ na estação chuvosa, e de $26,5^{\circ} \mathrm{C}$ e $56,0 \%$ na estação seca (Figura 4B e 5B), nessa ordem. Resultados semelhantes foram registrados nessa mesma região entre julho/2015 a abril/2016 com valores médios de temperatura do ar de $26,8{ }^{\circ} \mathrm{C}$ e umidade relativa do ar de 79,3\% na estação chuvosa e 58,2\% na estação seca (SABINO et al., 2020). Os extremos de Tmáx e Tmín registrados em pleno sol, no período experimental, ocorreram na estação seca, sendo: $40,1^{\circ} \mathrm{C}$ às $14: 00 \mathrm{~h}$ (agosto) e $9,7^{\circ} \mathrm{C}$ entre 04:00 às 06:00 h (julho) (Figura 4A e 4C);

As maiores amplitudes térmicas e de variações de UR diárias em pleno sol ocorreram durante a estação seca (Figura 4A e 4C, Figura 5A e 5C). Esses valores corroboram com os resultados obtidos por Borella et al. (2020) e Monteiro et al. (2016) para essas mesmas condições ambientais, contudo, em diferentes períodos de avaliação. Nesse sentido, ocorreram pequenas variações de Tmáx (Figura 4A) e URmín (Figura 5C) em julho, que por sua vez, são justificadas pela maior incidência da fração direta da radiação global na superfície terrestre e ausência de precipitações nesse período (Figura 3C e 3D) (SOUZA et al., 2016), que aumentam a temperatura do ar diurna, e consequentemente, a máxima no período de estiagem. Além disso, nesse mesmo mês também foram registrados os menores valores de Tmín (Figura 4C), decorrentes do deslocamento de massas de ar frias com grande intensidade, que atingem a região (friagens).
A dinâmica da Tar e UR depende principalmente do balanço de radiação, seguida das movimentações de massas de ar, nebulosidade, ventos e precipitações pluviais (BERGAMASCHI; BERGONCI, 2017), além das configurações de uso e ocupação da superfície (SOUZA et al., 2017). Durante a estação chuvosa (verão), as amplitudes térmicas são menores e mais constantes, com amenização principalmente da temperatura máxima diária decorrente das oscilações das componentes direta e difusa da radiação global com a cobertura de céu (ZAMADEI et al., 2018). Nessa época do ano há maior concentração de nuvens e vapor d'água na atmosfera, que têm grande potencial de atenuar a radiação global (SOUZA et al., 2016).

Em contrapartida, na estação seca (inverno) ocorrem as maiores amplitudes térmicas diárias (Figura 4 e 5) em função da alta transmissividade atmosférica, baixa concentração de vapor d'água (SOUZA et a., 2016) e pela interação com as propriedades ótica dos aerossóis atmosféricos (PALÁCIOS et al., 2018). Essa dinâmica atmosférica gera grande variação dos níveis de calor latente na proximidade da superfície do solo, com ganhos energéticos durante o dia e perda de calor à noite pelo balanço de ondas longas, ou seja, elevação das temperaturas máximas e redução das temperaturas mínimas (BERGAMASCHI; BERGONCI, 2017).

A dinâmica micrometeorológica de Tar e UR foi semelhante entre as telas pretas e as telas coloridas. $\mathrm{Na}$ estação seca ocorreram maiores amplitudes térmicas, com significativa redução de Tmín. Foram registrados valores mínimos de $9,7^{\circ} \mathrm{C}$ para a condição de pleno sol; $9,3{ }^{\circ} \mathrm{C}$ nas 
telas preta e verde, 9,$2 ; 9,4$ e $9,1{ }^{\circ} \mathrm{C}$ nas telas termorefletora, vermelha e azul (Figura 6$)$.

Holcman; Sentelhas (2012) estudaram o microclima de estufas com $70 \%$ de sombreamento, na estação chuvosa da região noroeste de São Paulo (220 42' 40 " S e $47^{\circ} 37^{\prime} 30$ "W, altitude de $546 \mathrm{~m}$ ) e relataram que as variações internas da temperatura e umidade relativa do ar ocorreram em função da transmissividade da radiação solar medida em diferentes telas (preta, termorefletora, vermelha e azul); constataram ainda maior diferença da temperatura e umidade relativa do ar na tela azul.

A dinâmica da temperatura e umidade relativa do ar abaixo das telas de sombreamento, em níveis crescentes e espectrais da radiação solar, depende do balanço de radiação que ocorre dentro destes microambientes. Isso indica seletividade de comprimentos de onda transmitidos por cada tela, de modo que podem ter gerado amplitudes térmicas (calor sensível) maiores na tela azul quando comparadas com a condição de pleno sol (BORELLA et al., 2020).

Outro fator importante na dinâmica de Tar e UR está ligado à circulação de ar. Durante o dia, no ambiente natural "aberto" (pleno sol) ocorre movimentação e renovação das massas de ar de forma mais rápida, permitindo maior dissipação da energia (calor) e troca de umidade, resultando em temperatura e umidade relativa do ar mais baixas que no interior das telas de sombreamento. Nestas, por sua vez, os processos de convecção e advecção do ar atmosférico são limitados, resultando em menor troca de energia entre o ambiente externo e interno e maior armazenamento de energia, condicionando maiores temperatura e umidade nesses ambientes protegidos. Ahmed et al. (2019) constataram que em regiões áridas, a temperatura do ar é menor e a umidade relativa é maior no interior de estufas resfriadas por evaporação com relação ao ambiente externo.

A evolução diurna de Tar e UR são decorrentes da incidência da radiação solar próxima à superfície terrestre. $\mathrm{Na}$ condição de pleno sol, ocorreu um retardo de Tmáx, sendo registrados maiores valores às 14:00 $\mathrm{h}$, com defasagem de duas horas em relação ao pico máximo de radiação global ou saldo de radiação incidente. Sob as telas poliefinas pretas e coloridas, ocorreu uma antecipação da Tmáx diária e uma sincronização com o momento de maior incidência da radiação global (passagem meridional). Todavia, os valores de Tmáx em algumas telas de sombreamento foram constantes entre 12:00 e 15:00 h, sendo que neste caso, a transmissividade e seletividade da radiação solar pelas telas podem ter influenciado nas flutuações diárias de Tar.

Essa dinâmica decorre do aquecimento da atmosfera próxima à superfície terrestre que acontece principalmente por transporte de calor sensível, o qual conduz a um aumento na temperatura interna e sua variação dentro da estufa (AHEMD et al., 2016). Ahmed et al. (2019) verificaram que as maiores variações de Tar e UR interna em ambientes sombreados, são geralmente observadas juntamente com um pico de radiação solar, por volta do meio-dia, confirmando o evidenciado no presente estudo.

Inúmeros fatores podem interferir no microclima de ambientes protegidos, como a latitude, altitude, época do ano, intensidade e ângulo de incidência da radiação solar, além da composição química, arranjo/arquitetura, envelhecimento e degradação do material de cobertura, formato, tamanho e posição da estrutura no campo (CHOAB et al., 2019). As propriedades ópticas da atmosfera (poeira, aerossóis, gotículas de água) também desempenham papéis importantes nessa interferência (PALÁCIOS et al., 2018).

\subsection{Estimativas diárias de Tar e UR em pleno sol e nas condições de sombreamento \\ Os valores dos indicadores estatísticos MBE e RMSE} ficaram próximos de zero (0), indicando bom desempenho estatístico das regressões lineares geradas (calibradas), enquanto que o índice de Willmott, indicou um elevado grau de acurácia nas estimativas de Tar no interior das telas de sombreamento, independentemente da estação hídrica (valores de "d" superiores a 0,98) (Tabela 1).

Os coeficientes de determinação $\left(\mathrm{R}^{2}\right)$ dos modelos de estimativas de UR (máxima, média e mínima) variaram de 70 a $85 \%$ e de 51 a $98 \%$ nas estações seca e chuvosa; 92 a $99 \%$ e 11 a $86 \%$ nas transições seca-chuvosa e chuvosa-seca, respectivamente (Tabela 1 ). Nesse caso, as regressões entre UR em telas e UR em pleno sol apresentam-se limitadas, indicando que outros fatores associados ao tipo de tela, construção e outros elementos meteorológicos (como ventos) apresentam grande influência na dinâmica de UR, e que podem não terem sido considerados apenas pela regressão linear. A velocidade do vento é determinante para as trocas convectivas, além disso a resistência aerodinâmica das coberturas testadas influencia nessas trocas, principalmente em condições mais úmidas (ALLEN et al., 1998).

Houve efeito da sazonalidade hídrica sobre os modelos de estimativas de Tar e UR no interior das telas poliefinas pretas de sombreamento. No período chuvoso, ocorre maior variação nos níveis de radiação global diária decorrentes das flutuações de cobertura de céu por nuvens, resultando em variações na incidência das frações da radiação solar direta e difusa sobre a superfície terrestre (ZAMADEI et al., 2018), e consequentemente, refletem nas oscilações de Tar e UR tanto em pleno sol quanto nos ambientes protegidos. Essa grande variabilidade de condições energéticas na estação chuvosa e chuvosa-seca permite maior faixa de variação de valores de Tar e UR, e por sua vez, geram coeficientes lineares e angulares com melhores ajustes às condições locais, principalmente para Tar, ou seja, a concentração de valores muitos próximos da variável independente, reduz a faixa de aplicação da regressão linear ajustada.

Pelos valores de MBE, para UR, foram obtidas variações de $-0,83$ a $0,77 \%$ na estação seca; $-0,07$ a $1,05 \%$ na secachuva; 0,14 a $1,64 \%$ na chuvosa; e $-3,30$ a $0,04 \%$ na chuvosaseca. As maiores subestimativas ocorreram na transição chuva-seca em todos os microambientes, e mais expressivamente nas estimativas de URmín (-2,34 a -3,30 \%), consequentemente, houve maior espalhamento (RMSE) nessas mesmas condições (de 4,77 a 6,25 \%). Nas demais estações hídricas foram observadas menores espalhamentos, indicando que as estimativas são melhores para condições mais secas (Tabela 1).

Apesar disso, os resultados foram satisfatórios, com índice de ajuste dos modelos "d" oscilando entre 0,96 para regressões de estimativas de UR na transição chuva-seca, e de 0,99 para as demais estimativas e estações hídricas do ano (Tabela 1). Foram obtidas regressões lineares crescentes entre os valores observados e estimados de Tar e UR no interior das telas, independentemente do percentual de sombreamento e da cor da tela. Foram obtidos coeficientes lineares negativos apenas para Tmín, URmín e Tmáx, com exceção da estação chuvosa e chuvosa-seca. Não foram 
observados padrões de crescimento ou de decréscimo de coeficientes lineares e/ou angulares com o aumento do nível de sombreamento das telas pretas.

Para as telas coloridas (Tabela 2), os coeficientes de determinação $\left(\mathrm{R}^{2}\right)$ das regressões ajustadas foram superiores a 72 e $88 \%$ para Tar e UR, respectivamente. A maioria dessas equações subestimaram Tar e UR (vide MBE), todavia, ficaram bem próximos de zero $\left(-0,26\right.$ a $0,36{ }^{\circ} \mathrm{C}$ e $-0,58$ a $0,32 \%$, respectivamente). Os espalhamentos (RMSE) oscilaram de 0,44 a $1,26{ }^{\circ} \mathrm{C}$ e 1,22 a $2,30 \%$ (Tabela 2 ), sendo que os índices de Willmott (d) foram superiores a 0,99 , denotando boas estimativas para aplicações futuras das equações calibradas em preenchimento de falhas e análises ecofisiológicas, na estação seca da região.

\section{CONCLUSÕES}

A dinâmica diária da temperatura e umidade relativa do ar no interior de telas de sombreamento é dependente da sazonalidade hídrica de cada região e apresenta dinâmica semelhante à condição ambiente (pleno sol), ao longo do ano.

O sombreamento proporciona maior uniformidade dos valores de Tar e UR quando comparado com o pleno sol.

A utilização de equações estatísticas para estimativas de Tar e UR em ambientes sombreados (viveiros agroflorestais) mostra-se como uma boa opção, quando baseada em medidas de pleno sol (estações meteorológicas automáticas e/ou convencionais), independentemente da época do ano, na região de transição Cerrado-Amazônia brasileira.

A utilização de telas de sombreamento em viveiros agrícolas e florestais é dependente da relação custo-benefício das telas, da disponibilidade hídrica regional e das respostas ecofisiológicas de diferentes espécies, sendo, portanto, de responsabilidade do usuário a escolha da tela de sombreamento.

\section{AGRADECIMENTOS}

A Coordenação de Aperfeiçoamento de Pessoal de Nível Superior - Brasil (CAPES) pelo Código de Financiamento 001. Ao Conselho Nacional de Desenvolvimento Científico e Tecnológico (CNPq) pelo apoio com as bolsas de iniciação científica e bolsa produtividade (Processo 308784/2019-7).

\section{REFERÊNCIAS}

AHEMD, H. A.; AL-FARAJ, A. A.; ABDEL-GHANY, A. M. Shading greenhouses to improve the microclimate, energy and water saving in hot regions: A review. Scientia Horticulturae, Amsterdam, v. 201, p. 36-45, 2016.

DOI: http://dx.doi.org/10.1016/j.scienta.2016.01.030

AHMED, H. A.; YU-XIN, T.; QI-CHANG, Y.; AL-FARAJ, A. A.; ABDEL-GHANY, A. M. Spatial distribution of air temperature and relative humidity in the greenhouse as affected by external shading in arid climates. Journal of Integrative Agriculture, Amsterdam, v. 18, n. 12, p. 2869-2882, 2019. DOI: 10.1016/S2095-3119(19)625980.

ALLEN, R. G.; PEREIRA, L. S.; RAES, D; SMITH, M. Crop evapotranspiration: guidelines for computing crop water requirements. Food and Agriculture Organization of the United Nations - FAO Irrigation and Drainage Paper, Rome, Italy, 1998. 300p.
BALFAGÓN, D.; SENGUPTA, S.; GÓMEZ-CADENAS, A.; FRITSCHI, F.B.; AZAD, R.K.; MITTLER, R.; ZANDALINAS, S.I Jasmonic Acid Is Required for Plant Acclimation to a Combination of High Light and Heat Stress. Plant Physiology. Rockville - USA, v. 181, n. 4, p. 1668-1682, 2019. DOI: 10.1104/pp.19.00956

BERGAMASCHI, H.; BERGONCI, J. I. As plantas e o clima: princípios e aplicações. Guaíba: Agrolivros, 2017. 352p.

BORELLA, D. R.; SOUZA, A. P. de; SILVA, A. C. da; FELIPE, R. T. A.; SILVA, K. N. C.; SOUZA, J. H. G. DE. Thermal requirements and filocron of Dipteryx alata under shading levels in the Cerrado Amazon transtition. Scientia Plena, Aracajú, v. 16, n. 5, p. 1-15, 2020. DOI: 10.14808/sci.plena.2020.051702

BORELLA, D. R.; SOUZA, A. P. de; SILVA, A. C. da; PIZZATTO, M.; KEFFER, J. F.; LIMA, D. C. Water requirements of Dipteryx alata Vogel Seedlings at different solar radiation levels in Cerrado-Amazon transition. Tropical and Subtropical Agroecosystems, Yucatan, v. 23, n. 2, p. 1-13, 2020.

COSTA, E.; SANTO, T. L. E.; BATISTA, T. B.; CURI, T. M. R. C. Diferentes tipos de ambiente protegido e substratos na produção de pimenteiras. Horticultura Brasileira, Brasília, v. 35, n. 3, p. 458-466, 2017. DOI: http://dx.doi.org/10.1590/S0102-053620170324

CHOAB, N.; ALLOUHIB, A.; EL MAAKOULC, A.; KOUSKSOUD, T.; SAADEDDINEA, S.; JAMIL, A. Review on greenhouse microclimate and application: Design parameters, thermal modeling and simulation, climate controlling technologies. Solar Energy, Kidlington, v. 191, p. 109-137, 2019. DOI: https://doi.org/10.1016/j.solener.2019.08.042

GRAY, S. B.; BRADY, S. M. Plant developmental responses to climate change. Developmental Biology, San Diego, v. 419, p. 64-77, 2016. DOI: http://dx.doi.org/10.1016/j.ydbio.2016.07.023.

HATFIELD, J. L.; PRUEGER, J. H. Temperature extremes: Effect on plant growth and development. Weather and Climate Extremes, Amsterdam, v. 10, p. 4-10, 2015. DOI: http://dx.doi.org/10.1016/j.wace.2015.08.001

HOLCMAN, E.; SENTELHAS, P. C. Microclimate under different shading screens in greenhouses cultivated with bromeliads. Revista Brasileira de Engenharia Agrícola e Ambiental, Campina Grande, v. 16, n. 8, p. 858-863, 2012.

MARTIM, C. C.; ZAMADEI, T.; SOUZA, A. P. de; ALMEIDA, F. T. de; ZOLIN, C. A. Angström-Prescott coefficients and reference evapotranspiration in the Cerrado-Amazon transition region of Mato Grosso. Revista Brasileira de Climatologia, Curitiba, v. 26, p. 579-594, 2020.2 DOI: http://dx.doi.org/10.5380/abclima.v26i0

MONTEIRO, E. B.; SILVA, A. C. da; SOUZA, A. P. de; TANAKA, A. A.; FERNEDA, B. G.; MARTIM, C. C. Water requirements and crop coefficients of tropical forest seedlings in different shading conditions. Revista Brasileira de Engenharia Agrícola e Ambiental, Campina Grande, v. 20, n. 8, p. 709-715, 2016. DOI: http:/ /dx.doi.org/10.1590/18071929/agriambi.v20n8p709-715

PALÁCIOS, R. S.; SALLO, F. da S.; MARQUES, J. B.; SANTOS, A. C. A.; MENEZES, J. A.; BIUDES, M. S.; NOGUEIRA, J. de S. Spatiotemporal variability of the 
optical depth of aerosols in areas of the savannah and of the Pantanal in the central region of Brazil. Nativa, Sinop, v. 6, n. 1, p. 56-65, 2018. DOI: http://dx.doi.org/10.31413/nativa.v6i1.5153

SABINO, M.; FERNEDA, B. G.; MARTIM, C. C.; BOUVIÉ, L.; SILVA, C. C. da; SOUZA, A. P. de; SILVA, A. C. da; FELIPE, R. T. A. Initial growth of amazonian and brazilian Cerrado yellow ipe cultivated under different shading intensities and spectral wavelength. Interciência, Caracas, v. 45, n. 4, p. 183-191, 2020.

SANTOS, R. B.; SOUZA, A. P. de; SILVA, A. C. da; ALMEIDA, F. T. de; ARANTES, K. R.; SIQUEIRA, J. L. de. Planejamento da pulverização de fungicidas em função das variáveis meteorológicas na região de Sinop MT. Global Science and Technology, Rio Verde, v. 6, n. 1, p. 72-88, 2013.

SOUZA, A. P. de; MOTA, L. L. da; ZAMADEI, T.; MARTIM, C. C.; ALMEIDA, F. T. de; PAULINO, J. Climate classification and climatic water balance in Mato Grosso state, Brazil. Nativa, Sinop, v. 1, n. 1, p. 34-43, 2013. DOI: https://doi.org/10.31413/nativa.v1i1.1334

SOUZA, A. P. de; ZAMADEI, T.; MONTEIRO, E. B.; CASAVECCHIA, B. H. Atmospheric Transmissivity of the Global Radiation in the Amazonic Region of Mato Grosso. Revista Brasileira de Meteorologia, São José dos Campos, v. 31, n. 4 (suppl.), p. 639-648, 2016. DOI: http://dx.doi.org/10.1590/0102-7786312314b20150147

SOUZA, A. P. de; SILVA, A. C. da; TANAKA, A. A.; ULIANA, E. M.; ALMEIDA, F. T. de; KLAR, A. E.; GOMES, A. W. A. Global radiation by simplified models for the state of Mato Grosso, Brazil. Pesquisa Agropecuária Brasileira, Brasília, v. 52, n. 4, p. 215-227, 2017. DOI: $10.1590 /$ S0100-204X2017000400001

TEITEL, M. The effect of screened openings on greenhouse microclimate. Agricultural and Forest Meteorology, Amsterdam, v. 143, p. 159-175, 2007. DOI: 10.1016/j.agrformet.2007.01.005

ZAMADEI, T.; SOUZA, A. P. de; ESCOBEDO, J. F.; ALMEIDA, F. T. de. Estimation of daily diffuse radiation based on atmospheric transmissivity and insolation ratio in the Cerrado-Amazon transition. Revista Brasileira de Climatologia, Curitiba, v. 23, p. 134-151, 2018. DOI: http://dx.doi.org/10.5380/abclima.v23i0 